Journal of Climate, 2005, Vol 18, p 2903-2921

\title{
Maintenance of the Sea-Ice Edge
}

\author{
C. M. Bitz ${ }^{1}$, M. M. Holland ${ }^{2}$, E. C. Hunke ${ }^{3}$, and R. E. Moritz ${ }^{1}$
}

Abstract. A coupled global climate model is used to evaluate processes that determine the equilibrium location of the sea-ice edge and its climatological annual cycle. The extent to which the wintertime ice edge departs from a symmetric ring around either pole depends primarily on coastlines, ice motion, and the melt rate at the ice-ocean interface. At any location the principal drivers of the oceanic heat flux that melts sea ice are absorbed solar radiation and the convergence of heat transported by ocean currents. The distance between the ice edge and the pole and the magnitude of the ocean heat flux convergence at the ice edge are inversely related. The chief exception to this rule is in the East Greenland Current, where the ocean heat flux convergence just east of the ice edge is relatively high but ice survives due to its swift southward motion and the protection of the cold southward flowing surface water. In regions where the ice edge extends relatively far equator-ward, absorbed solar radiation is the largest component of the ocean energy budget, and the large seasonal range of insolation causes the ice edge to traverse a large distance. In contrast at relatively high latitudes, the ocean heat flux convergence is the largest component and it has a relatively small annual range, so the ice edge traverses a much smaller distance there. When the model is subject to increased $\mathrm{CO}_{2}$ forcing up to twice pre-industrial levels, the ocean heat flux convergence weakens near the ice edge in most places. This weakening reduces the heat flux from the ocean to the base of the ice and tends to offset the effects of increased radiative forcing at the ice surface, so the ice edge retreats less than it would otherwise.

\section{Introduction}

Sea ice extent is an integral part of the high-latitude climate system through its influence on heat, moisture, and momentum exchange between the atmosphere and ocean. Reduced sea ice coverage causes poleward amplification of surface warming seen in climate simulations with increased greenhouse gases [Manabe and Stouffer, 1980; Ingram et al., 1989]. In addition, climate models show a striking sensitivity to sea ice anomalies prescribed in the North Atlantic [Smith et al., 2003; Chiang et al., 2003; Magnusdotter et al., 2004]. such as those that might have occurred on millennial timescales

Understanding processes that control the mean position and the annual march of the sea-ice edge is essential to attempt predicting the fate of the ice edge in a variable and changing climate. The position of the sea ice

\footnotetext{
${ }^{1}$ Polar Science Center, University of Washington, corresponding author's email: bitz@apl.washington.edu

${ }^{2}$ National Center for Atmospheric Research

${ }^{3}$ Los Alamos National Laboratory
}

edge is coupled mechanically and thermodynamically to the atmosphere and ocean. This study is concerned with deciphering the principal controls on the mean position of the ice edge and and its variability on centennial and longer timescales. Observational studies of sea ice indicate that on interannual timescales, variability in the extent is dominated by the atmospheric circulation [Walsh and Johnson, 1979; Fang and Wallace, 1994; Liu et al., 2002]. According to modeling studies, the ocean begins to play a role on longer time-scales [Holland et al., 2001a].

Sea ice is known to expand in early winter roughly to the mean position of the ocean thermal front in the Greenland and Norwegian Seas [Wadhams, 1981]. Early sea ice modeling studies attempted to identify the relative roles of ice dynamics and thermodynamics using sea ice models coupled to slab-ocean models with timeindependent oceanic heat flux and prescribed atmospheric forcing. An Arctic wide regional budget analysis of such a model conducted by Walsh et al. [1985] concluded that growth and melt generally contribute more 
in a given month to the seasonal cycle of ice mass than ice advection. Coupled ice-ocean modeling studies identified ocean heat transport as the chief cause of melting at the ice edge in the Nordic Seas [Hibler III and Bryan, 1987; Semtner, 1987]. Untersteiner [1988] constructed a similar picture for Fram Strait based on observations.

Similar questions have been raised about the position of the ice edge in the southern hemisphere. A study by Hibler and Ackley [1983] of the Weddell Sea compared models of dynamic and motionless sea ice and indicated that the ice advance was mainly thermodynamically driven, but the retreat was more rapid when the ice had lead openings, which result from ice dynamics.

Cooling at the ice edge and growth/melt influence ocean stability and and heat transfer in the ocean [Rudels, 1989; Martinson, 1990; Visbeck et al., 1995], making it difficult to prove a causal relationship between ice transport, oceanic heat transport, and sea ice extent from models. Winton [2003] attempted to make sense of the relationship between the latter two using a coupled climate model but with specified ocean currents. With this particularly novel approach, Winton found that doubling the speed of the currents in his model caused the ice extent to recede by $50 \%$, thereby showing sea ice coverage depends sensitively on ocean heat transport. Investigations of sea ice advance in response to greatly reduced insolation show somewhat contradictory results: Poulsen et al. [2001] concluded that ocean heat transport prevented sea ice from advancing beyond midlatitudes, while Lewis et al. [2003] found that the location of deep convection and ocean heat transport moved with the ice edge.

In this study we investigate what controls spatial variations in the mean position and seasonal march of the ice edge in the present day climate as an analog for what controls the mean position of the ice edge on centennial and longer timescales. We seek to understand why the ice edge spans $25^{\circ}$ of latitude across the North Atlantic Ocean in winter and why it spans only $15^{\circ}$ of latitude in the North Pacific. We shall also examine the tremendous annual range of sea ice extent in the South Atlantic sector of the Southern Ocean in the present day climate. It is our hope that by understanding the conditions that allow sea ice to exist in a range of environments today, we shall better understand how sea ice behaves in a changing climate.

We use the Community Climate System Model version 2 to estimate ice mass and heat budgets. We analyze simulations for both present day climate and an idealized future projection with a $1 \%$ increase in $\mathrm{CO}_{2}$ per year. In particular, we identify the extent to which the ice edge in each hemispheres is controlled by advection, deformation, and atmospheric and oceanic heat fluxes in the model. The model provides a selfconsistent and complete data set. An analysis of ob- servations with the same level of detail is impossible. We know that there are errors in our model's climate, and our analysis is one step toward understanding the reasons for our model's biases.

\section{Model Description}

We use version 2 of the Community Climate System Model (CCSM2) [Kiehl and Gent, 2004] because it has relatively advanced sea ice and ocean components by global modeling standards and it does not use flux adjustments. Here we briefly describe the model physics of each component. Specific details regarding the budget equations used for analysis in this study are given in the next section.

The sea ice model resolves a distribution of ice thicknesses using multiple ice categories, each having a unique and variable concentration and thickness of ice and snow and a unique surface energy balance and vertical temperature profile [Bitz et al., 2001; Lipscomb, 2001]. The model momentum equation includes the elastic-viscous-plastic stress tensor of Hunke and Dukowicz [2002]. The model also employs an explicit brine pocket parameterization with shortwave radiative transfer through the ice [Bitz and Lipscomb, 1999]. The inclusion of ice dynamics, multi-layer thermodynamics, and an ice-thickness distribution have been shown to affect the climate (e.g., SSS and SAT) simulated by a coarse-resolution coupled model [Bitz et al., 2001; Holland et al., 2001b].

The ocean component of CCSM2 is the Parallel Ocean Program (POP) [Smith et al., 1992]. Vertical mixing is accomplished with the K-profile parameterization scheme of Large et al. [1994], which includes the effects of shear mixing. Mixing along isopycnal surfaces by mesoscale eddies is parameterized using the method of Gent and McWilliams [1990] with the modifications of Visbeck et al. [1997].

The ocean and sea ice share a common grid. In the southern hemisphere the grid is spherical, but in the northern hemisphere the pole is displaced to a point within Greenland, to avoid converging meridians at the geographical north pole. The horizontal grid has 320 x 384 points. The zonal resolution is $1.125^{\circ}$, and the meridional resolution is $0.54^{\circ}$, except in the subtropics and tropics where it is finer. There are 40 vertical ocean levels - the thickness of the first 9 levels range from 10-16 m, increasing with depth. Although this model resolves some mesoscale ocean eddies, Gent et al. [2002] found that the sea ice extent in the southern hemisphere was improved with the addition of a mesoscale eddymixing parameterization.

The atmosphere model is dynamically similar to previous versions of the Community Climate Model (CCM), but the cloud scheme now uses a prognostic liquid water formulation [Rasch and Kristjánsson, 
1998 ] and cloud coverage has been generalized to allow for maximum cloud overlap. The horizontal resolution is truncated spectrally at T42 and there are 26 vertical levels. The model is described in more detail by Collins et al. [2002]. The land model computes soil and snow temperature and hydrology and includes a runoff scheme [Bonan et al., 2002].

In this study, we analyze results from a $1000-y r$ control simulation with atmospheric carbon dioxide $\left(\mathrm{CO}_{2}\right)$ held fixed at the concentration of the 1990's. We also include results from an integration with $\mathrm{CO}_{2}$ increasing at the rate of $1 \%$ per year, which was initiated using output from year 220 of the control. We take averages from years $61-80$ of the integration with increasing $\mathrm{CO}_{2}$ to represent the mean conditions at the time of $\mathrm{CO}_{2}$ doubling, which occurs during year 70 . The control climate simulation was nearly equilibrated by year 220, although the oceanic circulation around Antarctica still exhibited a slow, weak trend. For this reason the results we present from the control integration use averages from years 281-300, to avoid misinterpreting this trend in the ocean circulation as a climate change due to doubling $\mathrm{CO}_{2}$. We verified all conclusions drawn solely from the control integration by repeating our analysis for the last century of the integration (not shown). Unfortunately after the experiments were completed, an error was discovered in the way $\mathrm{CO}_{2}$ was increased. In the atmosphere model, some calculations are performed with $\mathrm{CO}_{2}$ defined as a mass mixing ratio and others use a volume mixing ratio. Both quantities were intialized properly at $355 \mathrm{ppm}$ at the beginning of the run, but only the volume mixing ratio was increased at the rate of $1 \%$ per year. The mass mixing ratio was mistakenly held at its initial value. Gent and Danabasoglu [2004] estimated that this error underestimates the climate response to increasing $\mathrm{CO}_{2}$ by about $10 \%$.

\section{Budget Diagnostics}

For decades, climate scientists have attempted to describe and quantify ice edge dynamics. Untersteiner [1975] provided a useful conceptual picture, reproduced in Fig. 1, which emphasizes the dependence on ice thickness, as well as the basic heat exchange with the atmosphere and ocean and ice motion. In nature and in our model, the ice edge is not abrupt. Instead we define the ice edge as the $50 \%$ concentration in coverage. The ice advances when ice grows or is advected equator-ward of the $50 \%$ contour, and it recedes when ice melts or is advected poleward in the vicinity of the $50 \%$ contour. The rate that the edge moves depends on the net growth and transport and the gradient in the ice thickness near the edge.

If we accept the ideas of Untersteiner [1975], ice thickness influences the position of the ice edge, and so we must understand how it evolves. Ice thickness (aggregated over the sub-grid scale ice-thickness distri-

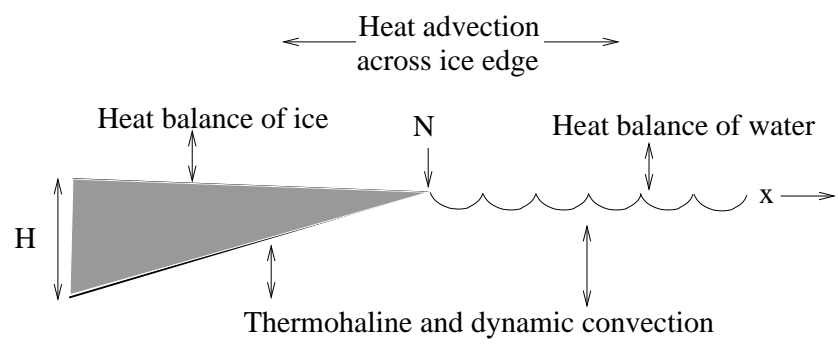

Figure 1. Schematic of ice edge dynamics, adapted from Untersteiner [1975]. The sea ice edge is governed by the balance equation $-d N / d t=G(N) /(d H / d x)$, where $d H / d x$ is the horizontal gradient in the mean thickness of the ice, $G$ is the net rate of growth (including advection), $N$ is the position of the ice edge, $H$ is the sea ice thickness.

bution) is governed by a continuity equations,

$$
\frac{\partial V}{\partial t}=-\nabla \cdot(\mathbf{u} V)+\mathcal{V}
$$

where $V$ is the ice volume (i.e., the mean ice thickness of the ice-thickness distribution including open water), $\mathbf{u}$ is the velocity of the ice and $\mathcal{V}$ is the contribution from thermodynamic processes. We assume that a large magnitude for either term in Eq. 1 indicates its controlling influence.

It is useful to further breakdown the thermodynamic contribution to the ice volume in terms of mass change at the top, bottom, and sides of the ice and new ice growth over open water. For each individual category when the top surface reaches the melting temperature, ice melts according to

$$
F_{\mathrm{AI}}-I_{0}-k \frac{\partial T}{\partial z}=-\left.q \frac{\partial H}{\partial t}\right|_{\mathrm{top}}
$$

where $F_{\mathrm{AI}}$ is the net flux from the atmosphere to the ice, $I_{0}$ is the solar radiation that passes through the upper surface of the ice, $k$ is the conductivity of ice, $\partial T / \partial z$ is the vertical temperature gradient at the surface, $q$ is the energy of melting, and $\partial H /\left.\partial t\right|_{\text {top }}$ is the melt rate at the top surface.

The bottom surface grows or melts according to

$$
F_{O I}+k \frac{\partial T}{\partial z}=-\left.q \frac{\partial H}{\partial t}\right|_{\text {basal }},
$$

where $F_{O I}$ is the flux from the ocean to the ice and $\partial H /\left.\partial t\right|_{\text {basal }}$ is the basal growth/melt rate. The oceanice flux depends on the departure of the top ocean level temperature $T_{0}$ from freezing $T_{f}$ according to Maykut and McPhee [1995]: $F_{O I}=c_{w} c_{h} u_{\tau}\left(T_{0}-T_{f}\right)$, where $c_{w}$ is the specific heat of sea water, $c_{h}=0.0058$ is an empirical constant, and the friction velocity $u_{\tau}$ is the squareroot of the magnitude of the kinematic Reynolds stress 

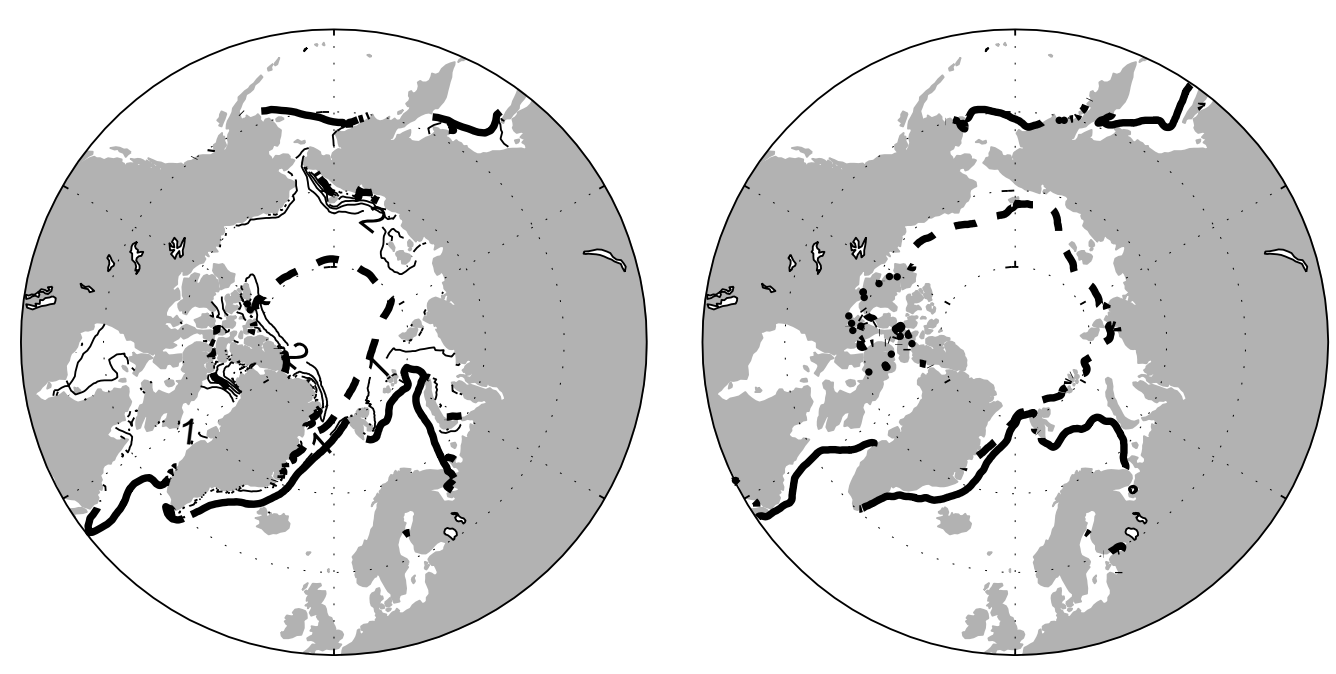

Figure 2. The April (solid) and September (dashed) position of the sea ice edge in the northern hemisphere in CCSM2 (left) and from passive microwave satellite observations (right). The left panel also shows the April ice thickness (in $1 \mathrm{~m}$ contours) from CCSM2. The position of the ice edge is defined as the $50 \%$ contour of the ice concentration.

at the ice-ocean interface. The model includes a parameterization of lateral melt that depends on the distribution of ice floes, as described in detail in Briegleb et al. [2002]. The lateral heat flux also depends on $T_{0}-T_{f}$.

Finally new ice growth over open water is determined by

$$
F_{i}=-\left.q \frac{\partial H}{\partial t}\right|_{\text {new }}
$$

where $F_{i}=\left(T_{f}-T_{0}\right) h$ is the flux needed to keep the temperature of the top ocean layer (of depth $h=10 \mathrm{~m}$ ) from falling below the freezing temperature.

As we shall see, the ocean energy budget plays an essential role in determining sea ice growth and melt rates, especially near the ice edge where ice can be advected into waters substantially above freezing. Although we are most interested in the ocean energy budget within the mixed layer, the equation is complicated by the time dependence of the mixed-layer depth. Hence we consider the budget of the entire vertical column of the ocean in our analysis,

$$
F_{\text {net }}-\int_{0}^{D} \nabla \cdot F_{\text {horiz }} d z-\int_{0}^{D} c_{w} \frac{\partial T_{w}}{\partial t} d z=0
$$

where $F_{\text {net }}$ is the net flux into the ocean surface, the second term is the vertically integrated horizontal ocean heat flux convergence (OHFC), and the third term is the change in heat content of the ocean column. The net flux into the ocean surface includes fluxes from the atmosphere and sea ice,

$$
F_{\text {net }}=(1-A) F_{\mathrm{AO}}+A\left(I_{b}+F_{b}+F_{l}\right)+F_{i},
$$

where $F_{\mathrm{AO}}$ is the net flux from the atmosphere to the ocean, $I_{b}$ is the shortwave radiation that penetrates through the sea ice, and $F_{b}$ and $F_{l}$ are basal and lateral heat fluxes to the sea ice. The OHFC has contributions from the total (Eulerian-mean and eddy-induced) advection and isopycnal diffusion. For simplicity, we compute the OHFC for the model as a residual from the other two terms in Eq. 5.

\section{Results}

\subsection{Northern Hemisphere}

The April and September positions of the sea ice edge in the northern hemisphere based on climatological monthly means, are shown in Fig. 2 for CCSM2 and for passive microwave satellite observations [Comiso, 1995]. Figure 2 also shows the April ice thickness from CCSM2. In April, roughly at its maximum, the ice edge in CCSM2 spans more than 25 degrees of latitude, while in September the ice edge is comparably quite zonal. The ice edge in CCSM2 is well positioned in April, although it is too far south by several degrees in parts of the Labrador Sea and the ice is not quite extensive enough in the Barents and Okhotsk Seas. The September ice edge is too far north, which reflects a thin bias in the model.

Figure 2 illustrates the relationship in CCSM2 between thickness and ice extent, which resembles the simple schematic in Fig. 1 from Untersteiner [1975]. The wintertime ice edge tends to extend farthest equatorward where the ice thickness gradient is lowest, such as in the Labrador Sea and Bering Sea. These are also regions where the annual range in the ice extent tends to be large. In contrast, the thickness gradient is high in the Greenland Sea, where the ice edge is relatively far 
(a) Fall Growth Rate

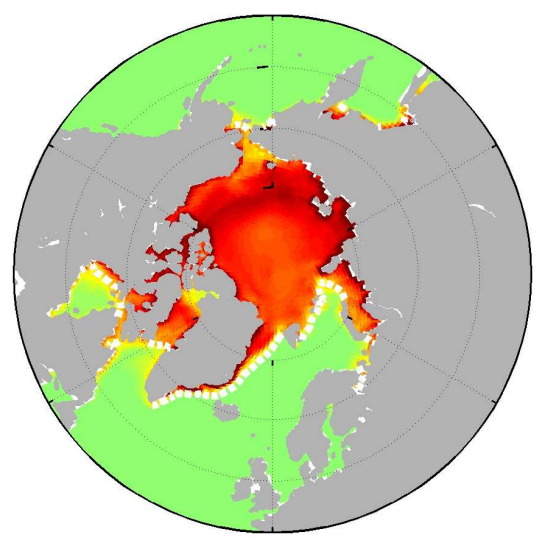

(b) Fall Basal+Lateral Melt

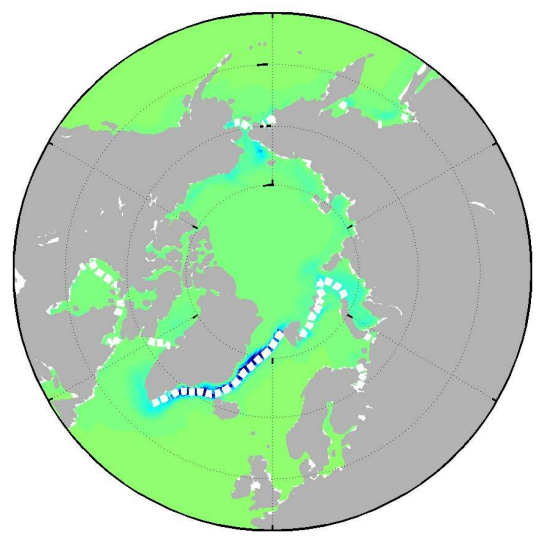

(c) Fall Convergence

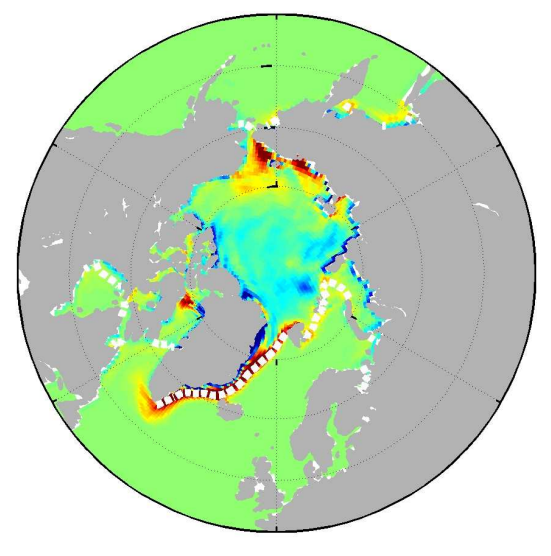

(d) Winter Growth Rate

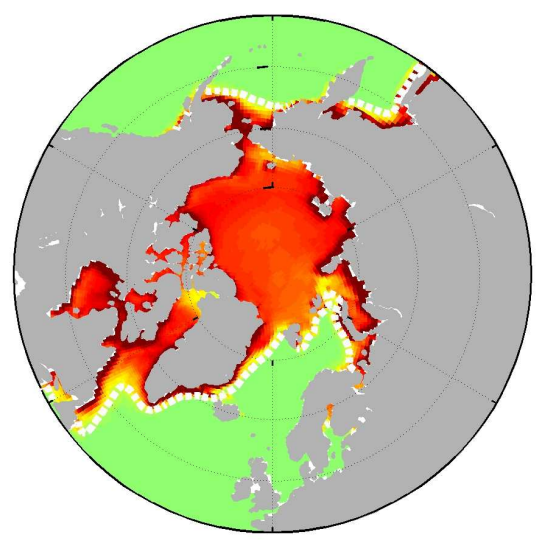

(e) Winter Basal+Lateral Melt

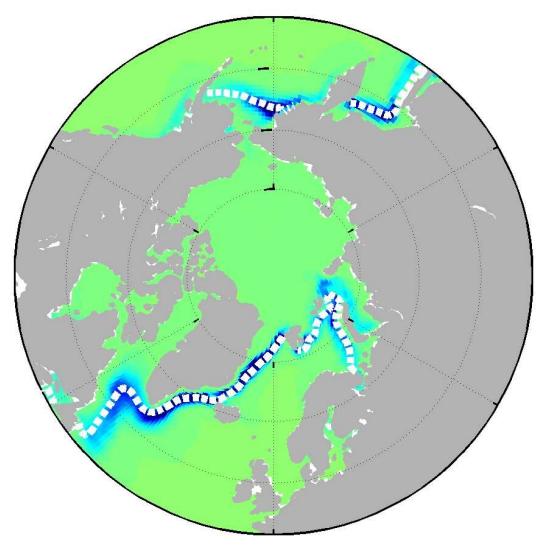

(f) Winter Convergence

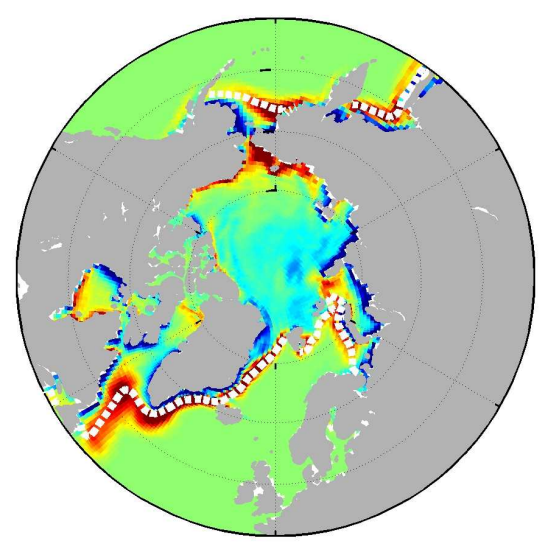

(g) Summer Top Surface Melt

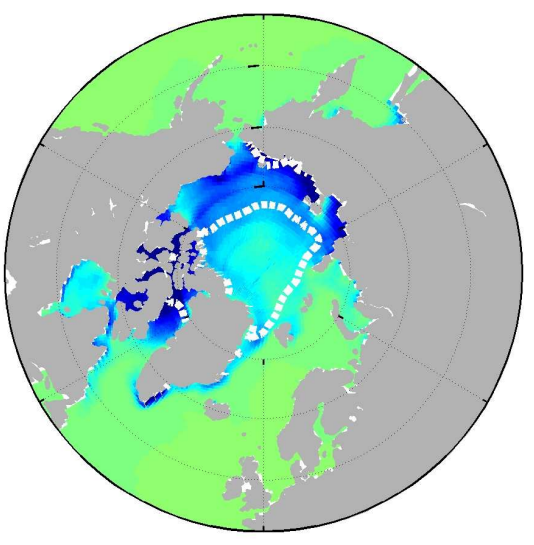

(h) Summer Basal+Lateral Melt

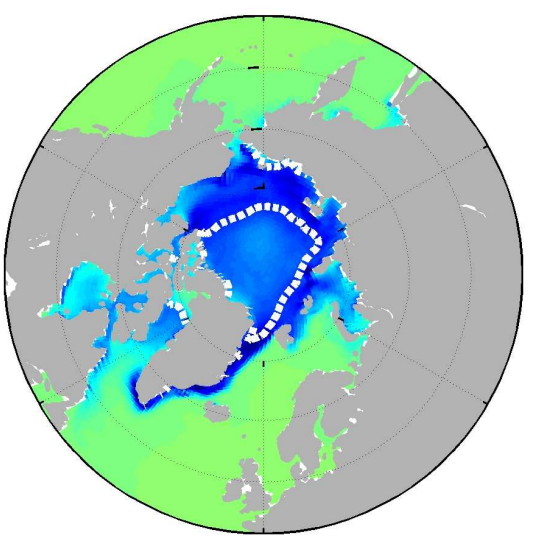

(i) Summer Convergence

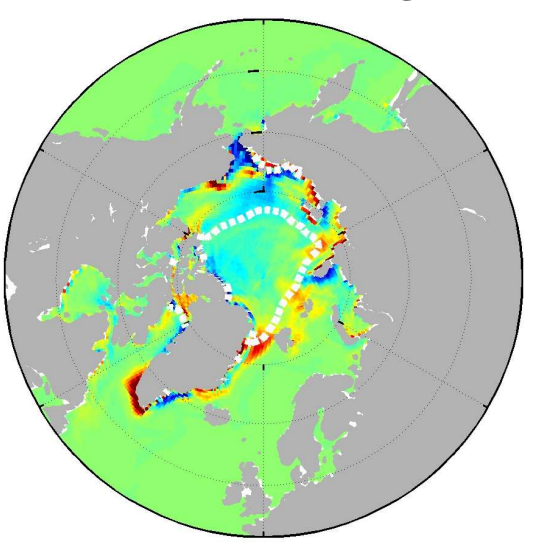

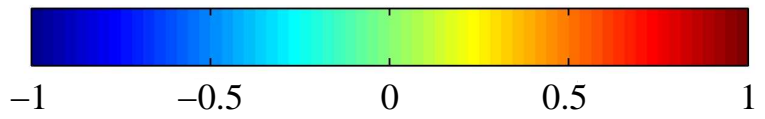

Figure 3. Terms in the ice volume budget (in $\mathrm{cm} \mathrm{s}^{-1}$, see Eq. 1) along with the position of the ice edge from CCSM2 in fall (Oct.-Dec.), winter (Jan.-Mar.) and summer (Jun.-Aug.). 
(a) Net Surface Flux

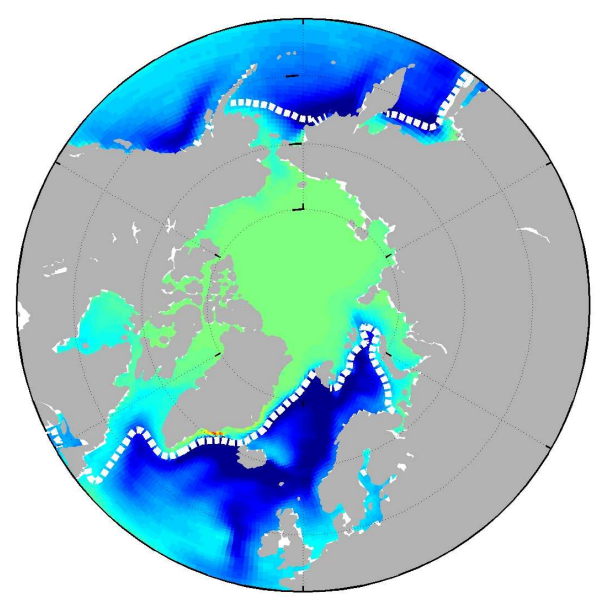

(b) Change in Heat Content

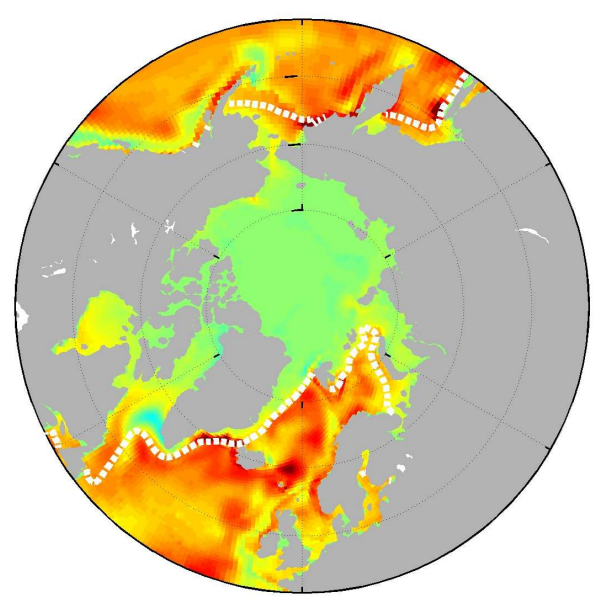

(c) Ocean Heat Flux Convergence

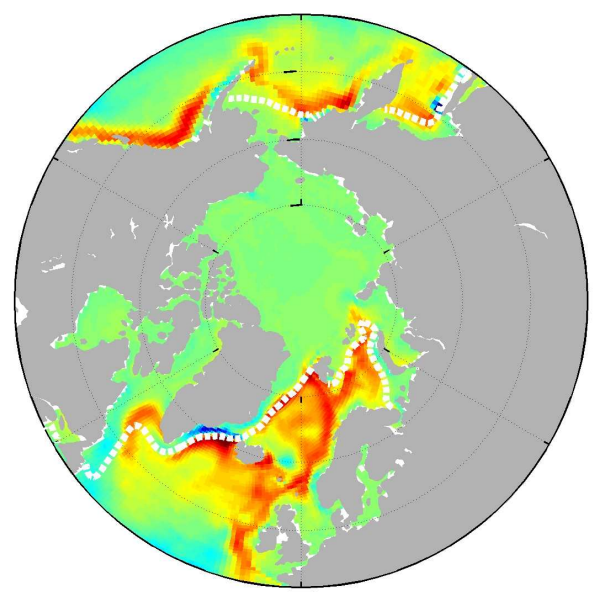

(d) Net Atmosphere-Ocean Flux

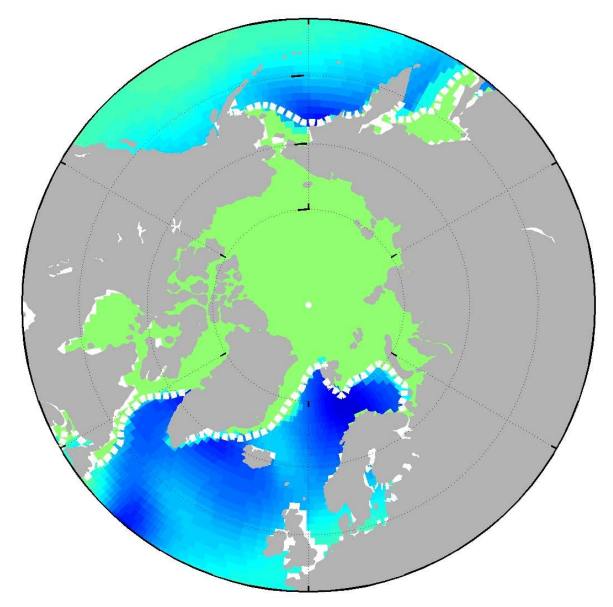

(e) Change in Heat Content - PHC

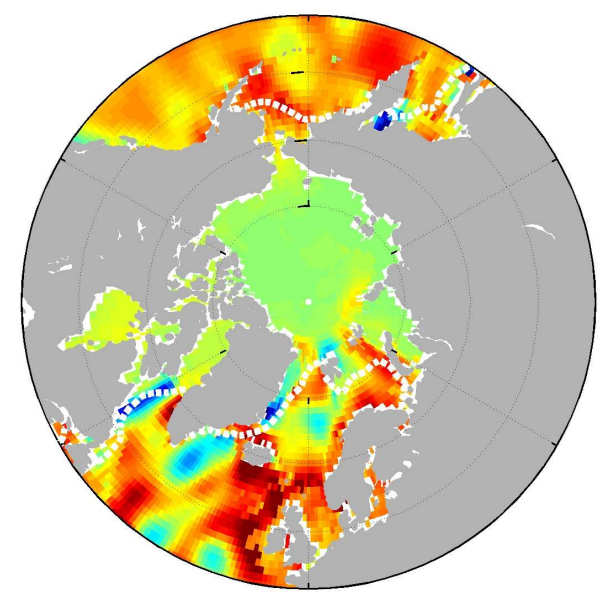

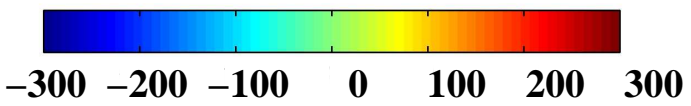

Figure 4. Winter (Jan.-Mar.) (a-c) are ocean heat budget terms (in $\mathrm{W} \mathrm{m}^{-2}$ ) from CCSM2 and observations (see Eq. 5, terms sum to zero) with ice edge from CCSM2. (d) shows the net atmosphere-ocean heat flux (excluding the ice-ocean flux) from the COADS dataset and (e) shows the change in heat content the PHC dataset, both with ice edge from satellite. 
north and changes little with season. The extreme melt back in the western Arctic in CCSM2 suggests that spatial variability in the melt rate and ice transport also influence the ice edge position, and so the ice thickness alone cannot explain the annual cycle of the ice edge position.

The thin bias in Fig.2a has been attributed to a general warm bias during winter over land and sea ice in the high northern latitudes by Kiehl and Gent [2004]. The bias is reduced in CCSM3, a more recent version of CCSM2 [Collins et al., 2005], owing to improvements in mixed-phase cloud physics and the subgrid-scale distribution of snow on land. The more recent model version still produces about the same wintertime ice extent, even though the ice is about twice as thick in the central Arctic Basin. However, the September ice meltback is reduced in CCSM3 because the ice thickness gradient in April $(d H / d x$ in Fig. 1) is larger in the new model.

4.1.1. Sea ice volume budget Next we evaluate growth and melt rates and ice convergence rates that give rise to the volume budget of sea ice in CCSM2. Figure 3 shows the key terms for Eq. 1 in fall (Oct.Dec.), winter (Jan.-Mar.) and summer (Jun.-Aug.) in CCSM2 along with the seasonal ice edge.

In agreement with satellite measurements [see, e.g., Parkinson et al., 1999], the ice edge in CCSM2 tends to advance rapidly in fall - typically more than half of the annual range is subtended locally in two months or less. This can be seen crudely in Fig. 3 by comparing the ice extent in the three seasons. The average ice edge position in fall is closer to the wintertime extent than the summertime extent. This is because sea surface temperatures (SST) in the marginal ice zone tend to be fairly homogeneous by the end of summer, and so the ice advances rapidly once SSTs reach the freezing temperature in fall.

In fall and winter, growth rates are about $0.5 \mathrm{~cm} \mathrm{day}^{-1}$ in the central Arctic and exceed $1 \mathrm{~cm} \mathrm{day}^{-1}$ along most coastlines where offshore winds create intermittent polyñya-like conditions, such as along the Siberian coast in the Laptev Sea (see Figs. 3a and d). Growth rates along western boundaries of ocean basins are particularly high as a result of cold air advection by northerly to northwesterly winds passing over continents and sea ice on the western side of the ocean basins, in association with the western branch of the Aleutian and Icelandic Lows.

Wintertime growth rates taper off in the zone of high ice convergence near the ice edge where high wintertime basal and lateral melt rates are also found in CCSM2 (see Fig. 3e), particularly in the West Spitzbergen and East Greenland Currents where melt exceeds 1 $\mathrm{cm} \mathrm{day}^{-1}$. Untersteiner [1988] described the under-ice boundary layer that develops in the Fram Strait where the ice edge meets a sharp gradient in the ocean surface temperature and the ocean currents oppose the ice motion. Untersteiner estimated the distance normal to the ice edge that is needed to cool the ocean to the freezing temperature (and hence the width of the melt zone) and found the distance was roughly $125 \mathrm{~km}$. This agrees roughly with the width of the melt zone at the ice edge in the Fram Strait and elsewhere in the northern hemisphere in CCSM2 (see Fig. 3b). Melt rates at the top surface of the ice are near zero everywhere in winter and hence are not shown.

Throughout the year sea ice is generally diverging from the interior of the pack and converging at the ice edge (Figs. 3c, f, and i), except in the Chukchi Sea where ice converges against the shore in the model in fall and winter. Divergence contributes about half as much as ice growth to volume changes in the Arctic in winter. Convergence of ice near the southern ice margin appears to play a mixed role in determining the distance between the ice edge and the pole in winter. For example, ice convergence tends to be high where ice exists in low latitudes such as the Labrador, Bering, and Okhots seas. However, the latitude of the ice edge within each of these three regions is not well correlated with local convergence rates. In some areas along the ice edge, basal and lateral melt tend to balance convergence, so the ice advances more slowly there.

In summer, basal plus lateral melt exceeds melt at the top surface in the Arctic Basin, except where summertime continental climates have a strong influence on the sea ice cover, such as in the Canadian Archipelago and in northern Baffin Bay (compare Fig. 3g and e). Comparable rates of basal and top surface melt were measured at SHEBA in 1997-1998: Perovich and Coauthers [1999] report approximately $100 \mathrm{~cm}$ of basal melt and $30 \mathrm{~cm}$ of top melt. However, the dominance of basal and lateral melt over surface melt in CCSM2 in the central Arctic and in observations at SHEBA are at odds with the measurements of Untersteiner [1961], who found on average $40 \mathrm{~cm}$ of melt at the top surface and $10 \mathrm{~cm}$ at the bottom. Observations of melt rates in the marginal ice zone are lacking, but sea ice models forced by observed atmospheric fields simulate melt rates much like those shown in Fig. 3 for CCSM2 [Steele and Flato, 1999].

The pattern of ice volume convergence in CCSM2 during summer (Fig. 3f) indicates there is net divergence from the central Arctic. However, the summer divergence pattern in CCSM2 may be unrealistic since the atmospheric winds over the Arctic Ocean have an anticyclonic bias in summer. Compared to winter, volume convergence appears to play a reduced role near the ice edge in summer.

The distance between the pole and the ice edge varies a great deal across ocean basins in winter, while the summertime ice edge is more zonal. In principle, the position of the wintertime ice edge in the northern hemisphere depends on the balance of ice dynamics, which 
advects ice toward the periphery of the ice pack, and basal and lateral melt, which is confined to a narrow band near the ice edge. There appears to be a fairly strong relationship between the latitude of the ice edge and ice convergence in the northern North Atlantic but not in the northern North Pacific.

The volume budget in Fig. 3 indicates wintertime melt near the ice edge overwhelmingly takes place at the base. According to Eq. 3, the basal melt (or growth) rate is the sum of the ocean-ice heat flux and the conductive flux. Because isotherms of surface air temperature in winter are roughly parallel to the ice edge, the conductive flux tends to be fairly homogeneous along the ice edge (not shown). In addition, lateral melt rates depend solely on the ocean-ice lateral heat flux because horizontal conduction in the ice interior is assumed negligible. For these reasons, we can conclude that the ocean-ice heat flux plays a key role in determining the ice edge position, with the caveat that we know rapid growth along western shores and advection in certain regions are also very important. Next we present a breakdown of the ocean heat budget to better understand the controls on basal and lateral melt.

4.1.2. Ocean Heat Budget The ocean energy budget in Eq. 5 is a balance of three terms: the net surface flux, the OHFC, and the change in heat content of the ocean. Figure $4 \mathrm{a}-\mathrm{c}$ shows the wintertime mean of these three terms with the wintertime ice edge from CCSM2. In winter the surface flux cools the ocean in the high northern latitudes, so its sign is given as negative. The sign convention for the other two terms was then chosen so the three terms sum to zero, as in Eq. 5 .

Our budget analysis resembles that of Seager et al. [2002], who used observations in the North Atlantic to argue that the ocean heat flux convergence in midlatitudes was insubstantial to explain the warm winters of western Europe compared to North America. Our analysis differs as we cover subpolar and polar regions and we focus on model results, which do not suffer from issues of data sparseness and/or quality.

To compare with CCSM2, Fig 4d shows wintertime observations of the atmosphere-ocean only portion of the surface flux $\left((1-A) F_{\mathrm{OA}}\right.$ in Eq. 6) from the Comprehensive Ocean-Atmosphere Data Set (COADS), based on observations from 1945-1989 [da Silva et al., 1994] and Fig 4e shows the change in heat content from the Polar Hydrographic Climatology (PHC), with temporal coverage from 1900-1994 [Steele et al., 2001]. Figures Fig $4 \mathrm{~d}$ and e are shown with the observed wintertime ice edge from passive microwave satellite data for the period 1979-2002. Observations of heat content and surface fluxes are too inaccurate to yield a reliable estimate of the wintertime OHFC as a residual.

Over ice-free regions, CCSM2 overestimates the magnitude of the surface flux in COADS just south of the ice edge by about $30 \%$, except offshore of Labrador where CCSM2 underestimates it. However, these are also regions where the COADS data are most sparse. The change in stored heat in the PHC is even more problematic. It seems unlikely that there should be any regions where the ocean heat content increases very much during winter, as seen in parts of the northern North Atlantic in Fig. 4e. If the magnitude of the stored heat in these regions is taken as an uncertainty in the data, the uncertainty is at least $100 \mathrm{~W} \mathrm{~m}^{-2}$. Nonetheless there are some regions where the change in stored heat in CCSM2 compares well with the PHC, like in the northern North Pacific.

In both model and nature, the ice edge in the northeast part of the North Atlantic is closest to the pole, except where it is obstructed by coastlines. This is not for lack of surface heat loss - the net surface flux is very negative there. Studies often conclude that large parts of the Greenland Iceland and Norwegian (GIN) seas are ice-free during winter because of heat transport into the region by the North Atlantic Current [Hibler III, 1986; Semtner, 1987]. The OHFC is a combination of heat transport by the Eulerian mean circulation and that which is induced by eddy motions. Danabasoglu [1998] showed that most of the heat transport in the northern hemisphere is due to the Eulerian mean circulation, and hence Fig. 4c shows that heat transport by the North Atlantic Current into the GIN seas is substantial. However, in wintertime the change in heat content of the ocean, shown in Fig. 4b, is similar in magnitude to the OHFC in the GIN seas (and much of the northern North Atlantic), which indicates that we must also consider the sources of ocean heating year-round. Indeed in the northern North Pacific, the wintertime change in heat content is typically much larger than the OHFC in the vicinity of the ice edge, except just south of Alaska where the OHFC reaches $\sim 200 \mathrm{~W} \mathrm{~m} \mathrm{~m}^{-2}$. Only about 10 $\mathrm{W} \mathrm{m} \mathrm{m}^{-2}$ of heat sustained for a year is needed to melt one meter of ice, assuming $100 \%$ ice coverage, and so it is not surprising that the OHFC must be quite small under compact ice, typical of the Arctic. $10 \mathrm{~W} \mathrm{~m}^{-2}$ is tiny compared to typical OHFC just south of the ice edge, and so it seems likely that the OHFC could have a very strong influence on the ice edge location.

The terms in the ocean heat budget and the position of the ice edge appear mutually related in the northern hemisphere. The sharp reduction in the surface heat flux is due to the excellent insulating quality of sea ice. Because surface heat loss is so small and a strong halocline exists under Arctic sea ice, the ocean convects only weakly under sea ice. Yet vigorous convection occurs adjacent to the ice edge, particularly in the GIN seas, owing in part to cold off-ice winds. Such a large horizontal gradient in convective strength influences the ocean heat transport near the ice edge. According to Fig. 4c the OHFC is small under ice in the Arctic in CCSM2, and it is often sharply peaked adjacent to the ice edge. 
(a) Net Absorbed SW

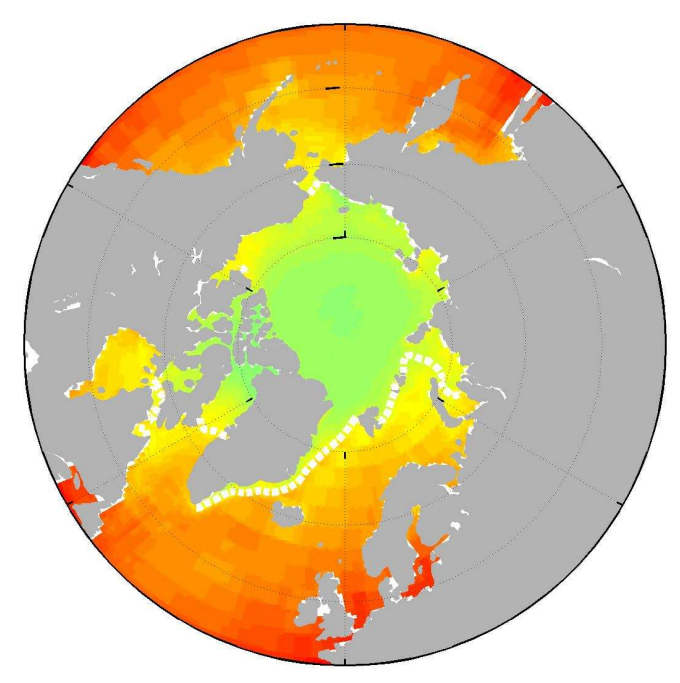

(b) Net Surface Flux
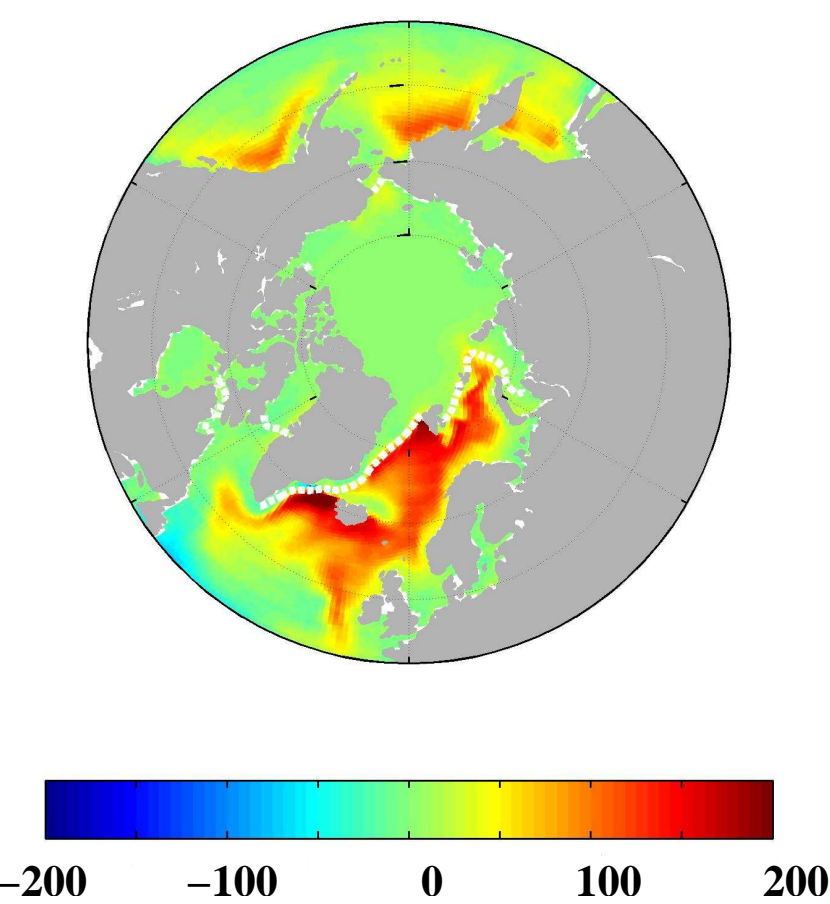

(c) Net Absorbed SW

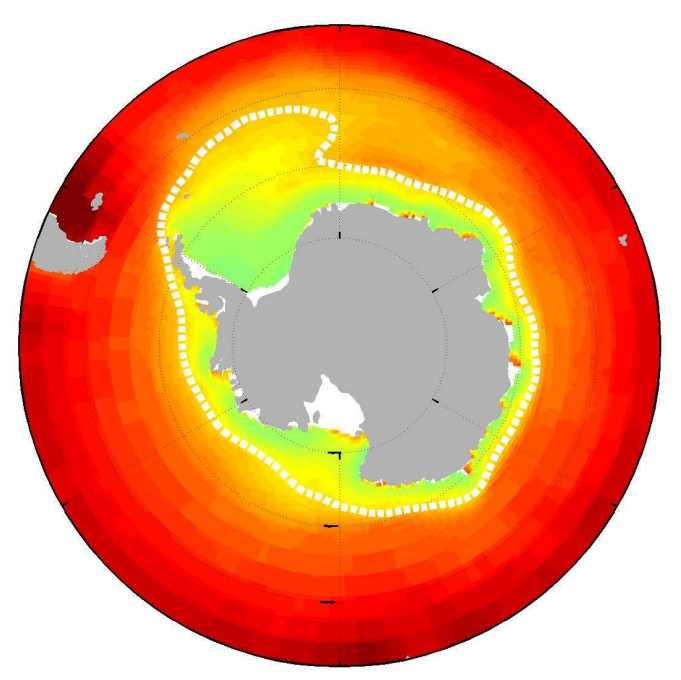

(d) Net Surface Flux
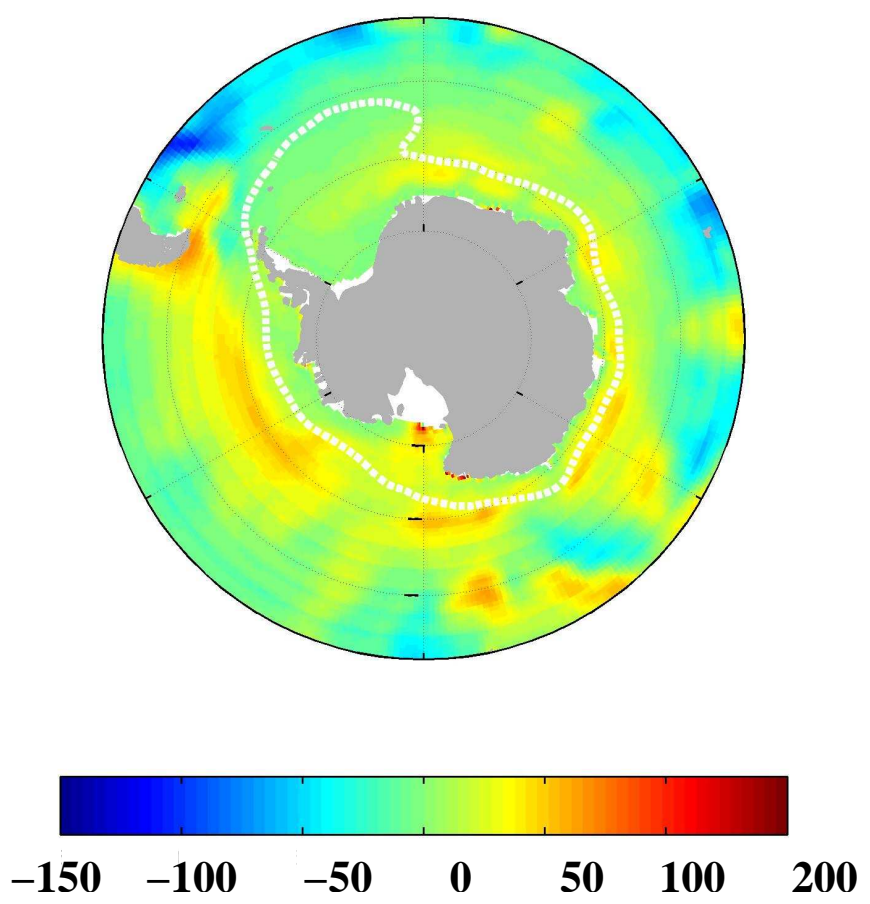

Figure 5. Annual means of sources of heating to the ocean heat budget (in $\mathrm{W} \mathrm{m}^{-2}$ ) with the ice edge from CCSM2. 

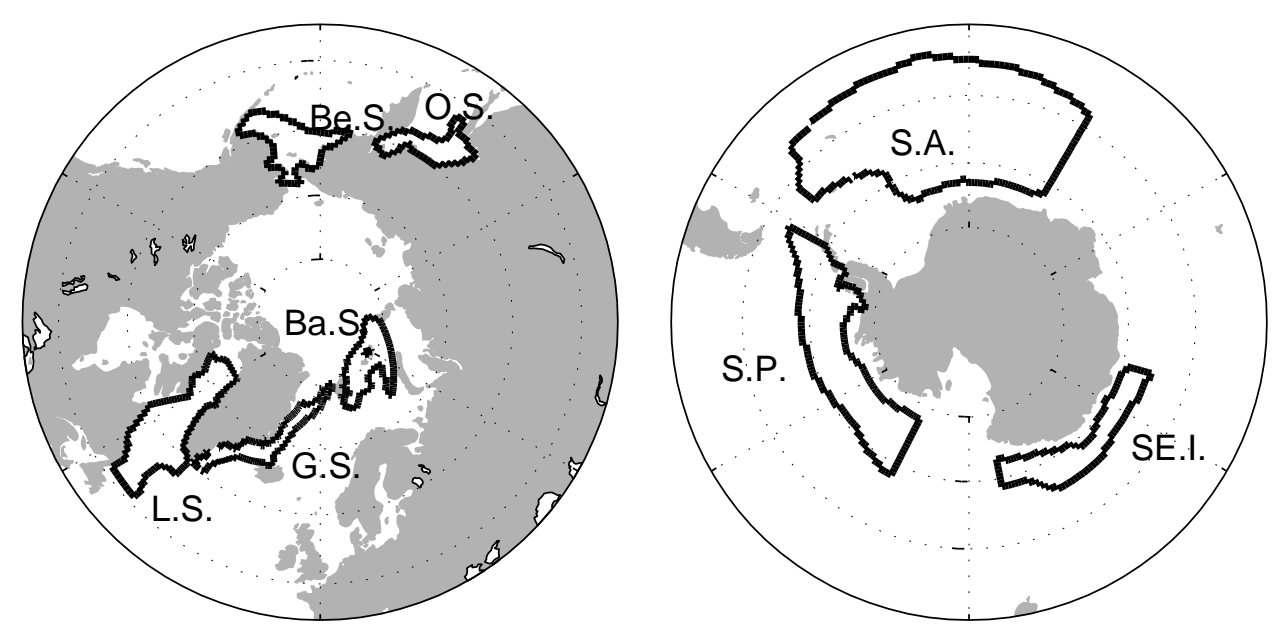

Figure 6. Ice regions used for averages in Table 1.

Table 1. Relative sources of ocean heating in CCSM2 averaged over regions identified in Fig. 6.

\begin{tabular}{lrr} 
Region & Absorbed Shortwave & OHFC \\
& $\%$ & $\%$ \\
\hline \hline Barents Sea & 37 & 63 \\
Greenland Sea & 40 & 60 \\
Labrador Sea & 80 & 20 \\
Bering Sea & 64 & 36 \\
Okhotsk Sea & 67 & 33 \\
South Atlantic & 83 & 17 \\
Southeast Indian & 58 & 42 \\
South Pacific & 65 & 35
\end{tabular}

The main sources of ocean heating are solar absorption and the OHFC. While solar absorption only supplies heat in summer, the OHFC is substantial yearround in much of the northern North Atlantic. Figure $5 \mathrm{a}$ and $\mathrm{b}$ show the annual-mean fields for these two components. Unsurprisingly, solar absorption is quite zonal because the sea ice edge and contours of ice concentration are also nearly zonal in summer. The annual mean OHFC is even larger than the wintertime value in some regions where strong westerly winds cause southerly Ekman drift in the surface currents that peaks in winter, as discussed in Seager et al. [2002].

Regional variations in these sources of ocean heat affect the latitude of the ice edge. On the large-scale in the northern North Atlantic, Fig. 5b shows that the OHFC in the ice-covered Labrador Sea is $\sim 200 \mathrm{~W} \mathrm{~m}^{-2}$ less than the ice-free southern Barents Sea, which overwhelms the difference in solar absorption. Quite remarkable, however, is that outside of the East Greenland Current and shallow shelf regions, the OHFC is rather homogeneous in the GIN seas. It is possible that nearly the whole of the GIN seas would be ice-free in
CCSM2, if it were not for the large volume of ice entering the region through Fram Strait and the protection from the North Atlantic Current that the ice gains in the East Greenland Current.

Figure 5 can also be used to identify the relative proportions of ocean heating by solar absorption and the OHFC on the annual mean. Table 1 gives the relative contribution from these terms averaged over the marginal ice zone by region as identified in Fig. 6. The regions were selected as representative of areas within the marginal ice zone with relatively common behavior, such as the area traversed by the ice edge in the Barents Sea, excluding areas within a few hundred kilometers of the coast. According to Table 1, the OHFC is a relatively large source of heating in the marginal ice zone of the Barents Sea and a relatively small source in the Labrador Sea. A rough correspondence exists between the relative amount of heating by the OHFC and the latitude of the region.

Fig. 7 shows a scatter plot of the latitude of the ice edge and the OHFC in the vicinity, for $1^{\circ}$ intervals of longitude in the northern hemisphere (see figure caption for more details). While all of the points taken together are highly correlated $\left(r^{2}=0.49\right)$, it is not clear how to asses the number of independent degrees of freedom in the data. For this reason we use a simpler analysis that only attempts to show that the OHFC differs between groups of points that are clustered together. In addition, we exclude points in the East Greenland Current, as we have already noted that no simple relationship exists between the ice edge and OHFC there. In Fig. 7 , the points cluster roughly in two groups with latitudes less than $62^{\circ}$ (corresponding to the ice edge in the North Pacific and Labrador Sea) and and greater than $73^{\circ}$ (corresponding to the ice edge in the Barents Sea and Fram Strait. The mean OHFC for these two 


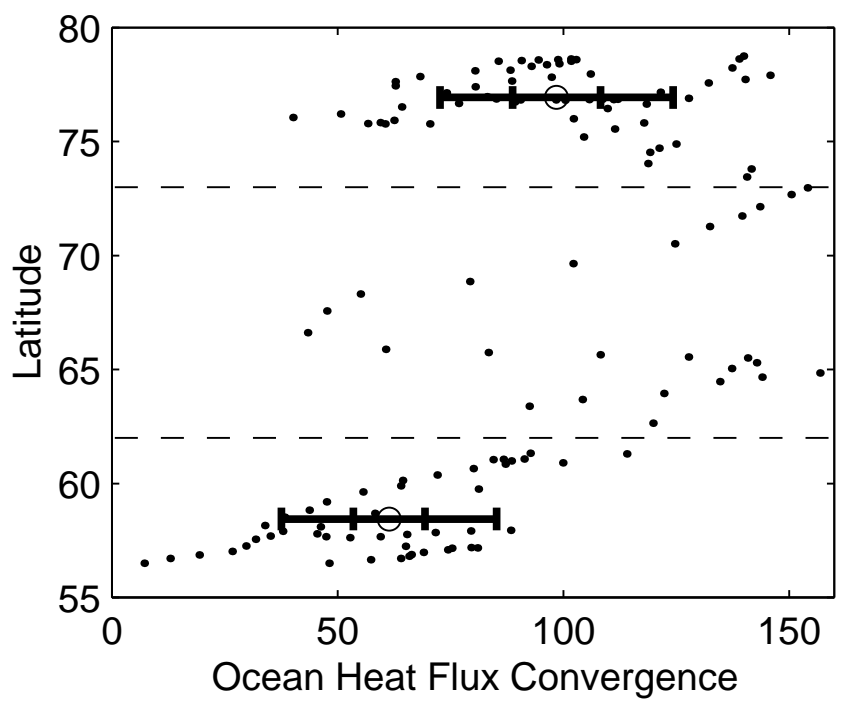

Figure 7. Scatter plot of the latitude of the ice edge in the northern hemisphere versus the ocean heat flux convergence in the same vicinity. The latitude of the ice edge is given along for $1^{\circ}$ intervals of longitude where unobstructed by coastlines and the OHFC is averaged at the same longitude interval and for latitudes beginning at the ice edge and spanning $3^{\circ}$ towards the equator. The points are split into groups south of $62^{\circ}$ and north of $73^{\circ} \mathrm{N}$, which exclude points in the Greenland Sea, and the average heat flux is shown for each group with an open circle. Error bars show the standard error and average error of the mean.

groups of points is significantly different at the $95 \%$ confidence level along the ice edge of the high and low latitude groups, which suggests that the OHFC plays a considerable role in establishing the latitudinal position of the ice edge.

\subsection{Southern Hemisphere}

The September and March positions of the sea ice edge in the southern hemisphere are shown in Fig. 8 for CCSM2 and for passive microwave satellite observations. In addition the September ice thickness is shown for CCSM2. The September ice edge in CCSM2 is too far north by $5-10^{\circ}$ in the South Atlantic, and elsewhere mostly CCSM2 is not quite extensive enough. Generally the wintertime ice cover in the southern hemisphere is less compact than in the northern hemisphere. The ice compactness in CCSM2 tends to be low in the southern South Atlantic and high elsewhere. In spite of the model biases, the September position of the ice edge in the southern hemisphere is more zonal than in the the northern hemisphere, and the ice edge spans a smaller interval of latitudes. In both model and observations, the ice edge in March tends to hug the continent, except in the Weddell Sea.
The relationship between ice thickness and ice edge position in Fig. 8 indicates that the summertime reduction in thickness is $2.5-3 \mathrm{~m}$ in some parts of the Southern Ocean. We will try to explain why this is the case by first evaluating the ice volume budget terms.

4.2.1. Sea ice volume budget Figure 9 shows the ice volume budget terms for the southern hemisphere in CCSM2. In fall and winter, growth rates are highest next to the continent in coastal polyñyalike features in the model (see Figs. 9a and d), where off-shore winds form a great deal of open water during winter (see Fig. 9c and f). In fall, the growth rates are much higher away from the continent than they are in winter. Consequently, the ice edge advances rapidly in fall and then advances comparably quite slowly in winter, as was the case in the northern hemisphere. Basal and lateral melt rates at the ice edge also conspire to reduce the ice advance in winter in some regions, although the melt rates are much more modest in the southern hemisphere than in the northern hemisphere. In addition, substantial melt rates are seen hundreds of kilometers from the ice edge in Antarctica, while melt rates were virtually zero at a similar distance from the ice edge in the Arctic. As in the northern hemisphere, top surface melt rates are negligible in winter in the southern hemisphere (not shown).

Net convergence of the ice pack increases the ice volume throughout most of the marginal ice zone in the South Atlantic sector in fall and winter (see Figs. 9c and $\mathrm{f}$ ). A noteworthy semi-circle of high ice convergence brackets the eastern half of Antarctica, in the transition region between the Antarctic Coastal Current and the Antarctic Circumpolar Current, which circle in opposite directions around the continent.

In summer, basal plus lateral melt exceeds melt at the top surface everywhere in the southern hemisphere (compare Fig. 9g and h). The top surface melts very little anytime in the southern hemisphere in CCSM2, consistent with the observations reported by Gordon [1981]. The melt pattern in Fig. 9h depends mostly on the late winter ice thickness (Fig. 8), and hence the availability of ice to melt. Although the ice is too extensive in winter in the South Atlantic, much of the ice melts-away in summer owing to high basal melting rates.

Summertime ice transport depletes the ice throughout most of the marginal ice zone and builds it up along the east Antarctic coast. as the ice motion in the narrow ring around the continent takes on a southerly component (see Fig. 9f). Ice around the rest of Antarctica is also typically converging towards the continent, but in a very inhomogeneous fashion.

The unique features in the volume budget in the southern hemisphere compared to northern hemisphere are the tendency for substantial wintertime melting under regions even far from the ice edge, the near absence 

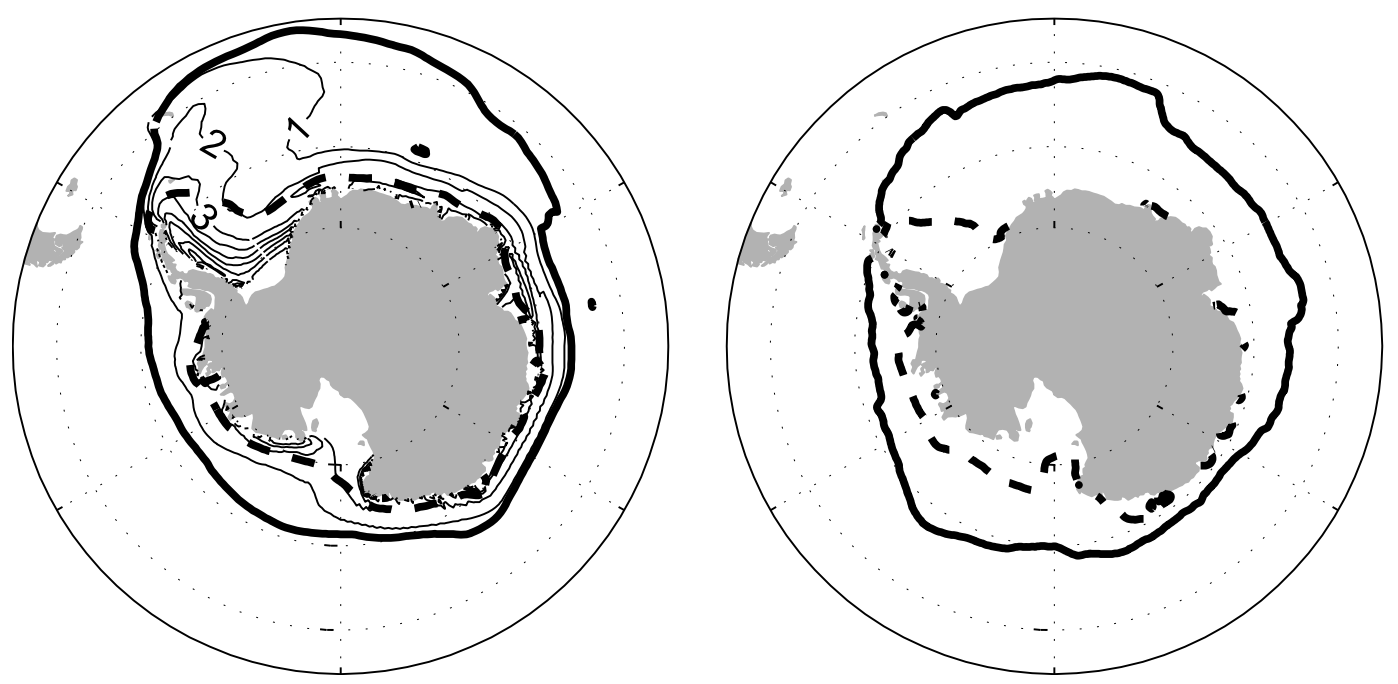

Figure 8. The September (solid) and March (dashed) position of the sea ice edge in the southern hemisphere in CCSM2 (left) and from passive microwave satellite observations (right). The left panel also shows the September ice thickness (in $1 \mathrm{~m}$ contours) from CCSM2. The position of the ice edge is defined as the $50 \%$ contour of the ice concentration.

of melt at the top surface even in summer, and the very large reduction in ice thickness in some regions. The lack of top surface melting can be attributed to the deep snow cover on the ice, and the near absence of snow-free land (which might otherwise warm-up) in the vicinity during summer. Consequently the ice surface tends to remain snow covered, until the ice disappears by lateral and basal melt. Around east Antarctica, transport in summer provides a large sink of ice locally at the ice edge and gives rise to a large reduction in ice thickness and extent there. Wintertime melting far from the ice edge can only be understood by taking a closer look at the ocean heat budget, which we discuss next.

4.2.2. Ocean Heat Budget The terms from the ocean heat budget (Eq. 5) of CCSM2 in winter are shown in Fig. 10. Unfortunately observations in the southern hemisphere are too sporadic to produce a useful picture for comparison. As in the northern hemisphere, meridional variations in the ice edge depend little on the wintertime ocean-atmosphere surface heat loss, otherwise we would expect the ice to be more extensive in the Pacific. The other two terms in the ocean heat budget in winter (see Fig. 10b and c) show that the change in heat content is typically about a factor of five higher than the OHFC along the ice edge. The change in heat content is fairly uniform along the ice edge. In contrast, the OHFC is considerably smaller, even negative, where the ice edge is farthest north. Beneath the ice, the OHFC averages about $12 \mathrm{~W} \mathrm{~m}^{-2}$ in CCSM2.

In the presence of sea ice, the annual-mean OHFC is equal to the near-surface vertical heat flux in the ocean, provided the ocean heat content is in steady-state. The
OHFC in CCSM2 is similar to estimates of the vertical heat flux needed to maintain the seasonal sea ice cover around Antarctica in other modeling work [Parkinson and Washington, 1979; Martinson, 1990]. Observational estimates of the near-surface vertical heat flux in the Southern Ocean are mostly limited to the Weddell Sea in winter, where values range from 23 to $52 \mathrm{~W} \mathrm{~m}^{-2}$ [Gordon and Huber, 1990; McPhee et al., 1999] in the east to about $7 \mathrm{~W} \mathrm{~m}^{-2}$ in the west [Lytle and Ackley, 1996]. The east-west variation in vertical heat flux coincides with the observed east-west thermal front in the ocean below the pycnocline, where Weddell Deep Water lies [Gordon and Huber, 1984]. The pattern of the flux in the model (not shown) has low values extending north and east of the Maud Rise (roughly $65^{\circ} \mathrm{S}$ and $0^{\circ} \mathrm{E}$ ), which encourages the ice coverage to be greater than is observed in that area.

Annual means of the two main sources of ocean heating in the southern hemisphere are shown in Fig. 5c and $\mathrm{d}$. Both components are fairly zonal, except in the South Atlantic sector. Clearly solar absorption is the larger component at the ice edge in the southern hemisphere. Also the pattern of OHFC lacks the sharp increase immediately equator-ward of the ice edge that was seen in the northern hemisphere. The ocean under the ice in the southern hemisphere is generally less stratified and more prone to convect under ice than in the northern hemisphere, so the southern hemisphere lacks the large gradient in convective activity at the ice edge that is apparent in (see Fig. 5d and b).

Table 1 shows the relative proportions of the sources of heating to the ocean shown in Fig. $5 \mathrm{c}$ and d, averaged over various regions in the southern hemisphere that are 
(a) Fall Growth Rate

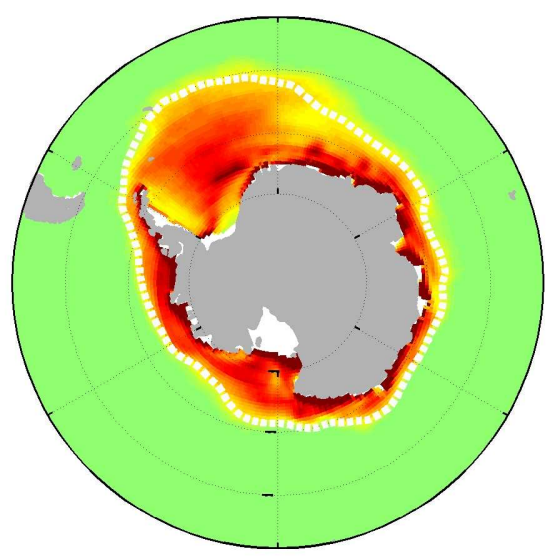

(b) Fall Basal+Lateral Melt

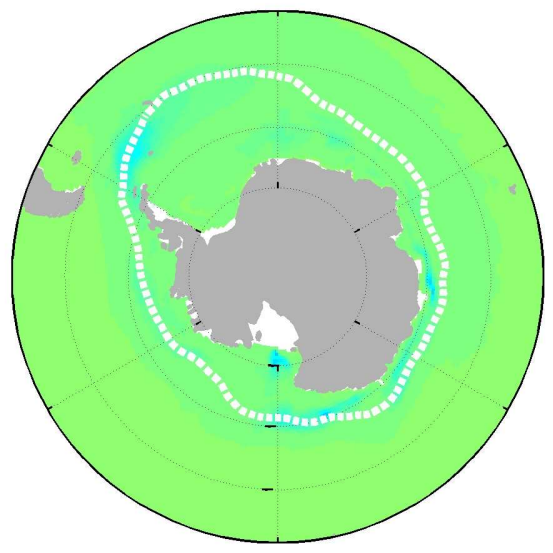

(c) Fall Convergence

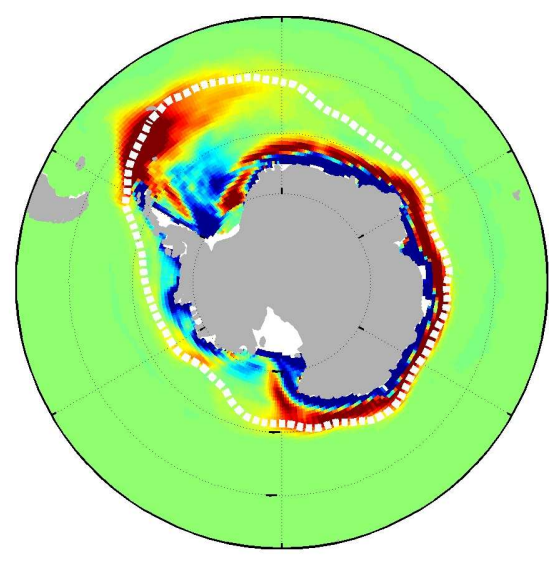

(d) Winter Growth Rate

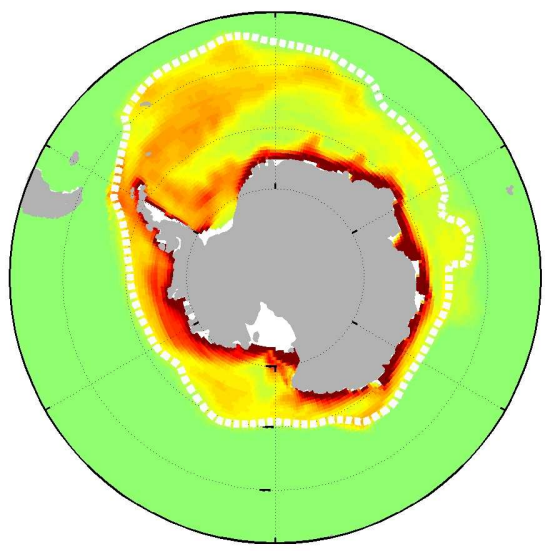

(e) Winter Basal+Lateral Melt

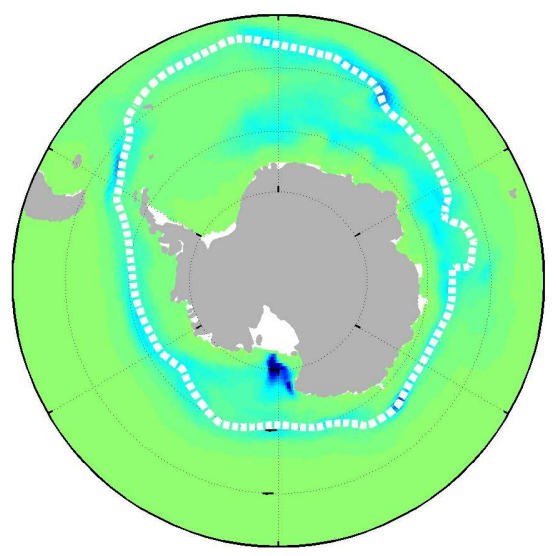

(f) Winter Convergence

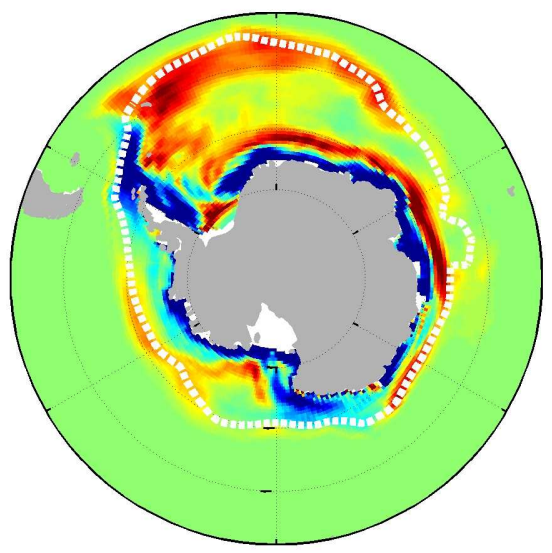

(g) Summer Top Surface Melt

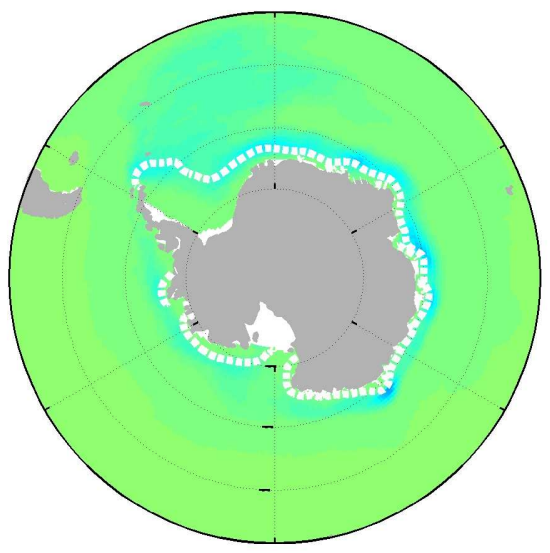

(h) Summer Basal+Lateral Melt

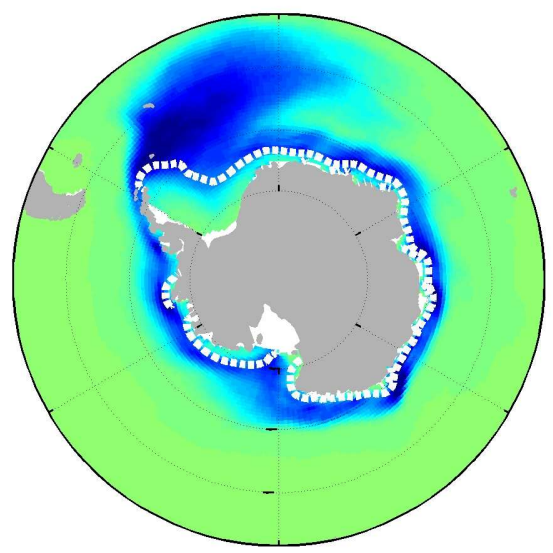

(i) Summer Convergence

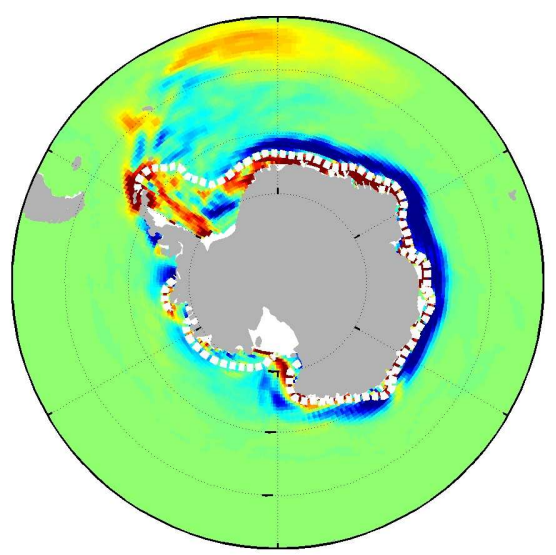

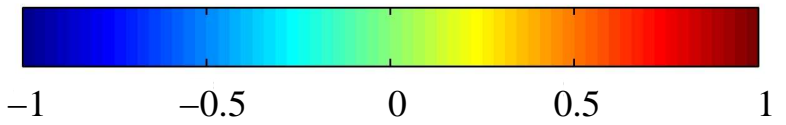

Figure 9. As in Fig. 3 but for the Southern Hemisphere, where fall is (Apr.-Jun.), winter is (Jul.-Sep.), and summer is (Dec.-Feb.). 
(a) Net Surface Flux

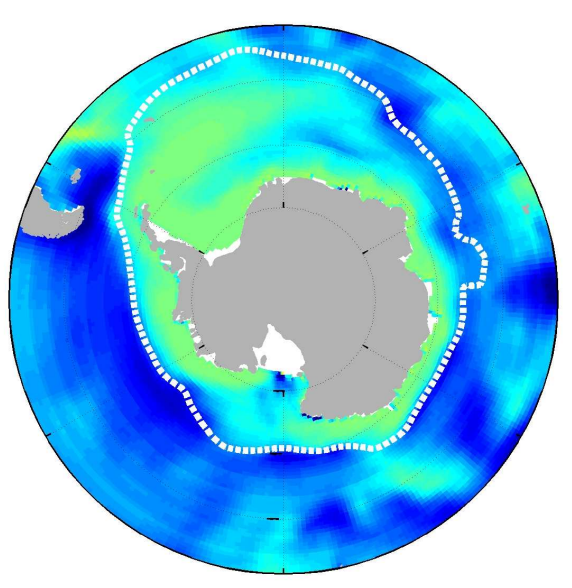

(b) Change in Heat Content

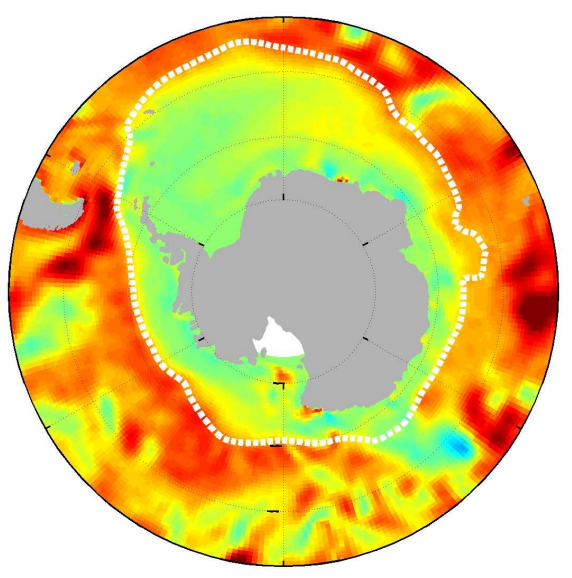

(c) Ocean Heat Flux Convergence
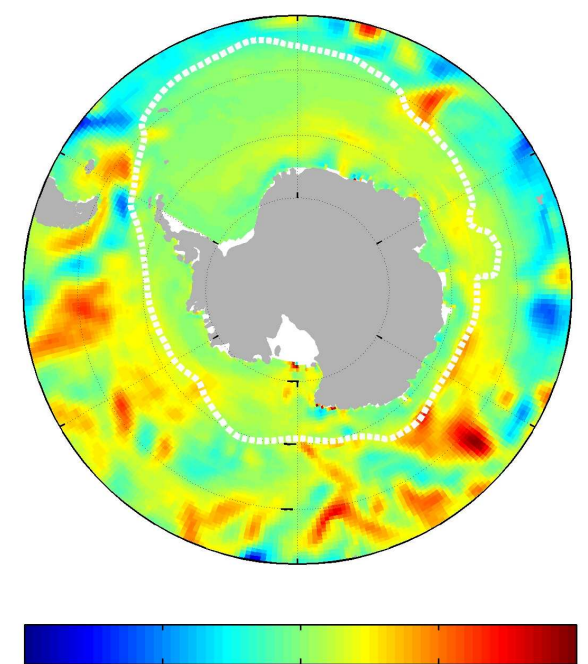

$\begin{array}{lllllll}-300 & -200 & -100 & 0 & 100 & 200 & 300\end{array}$

Figure 10. As in Fig. $4 \mathrm{a}-\mathrm{c}$ but for the southern hemisphere in months Jul.-Sep.

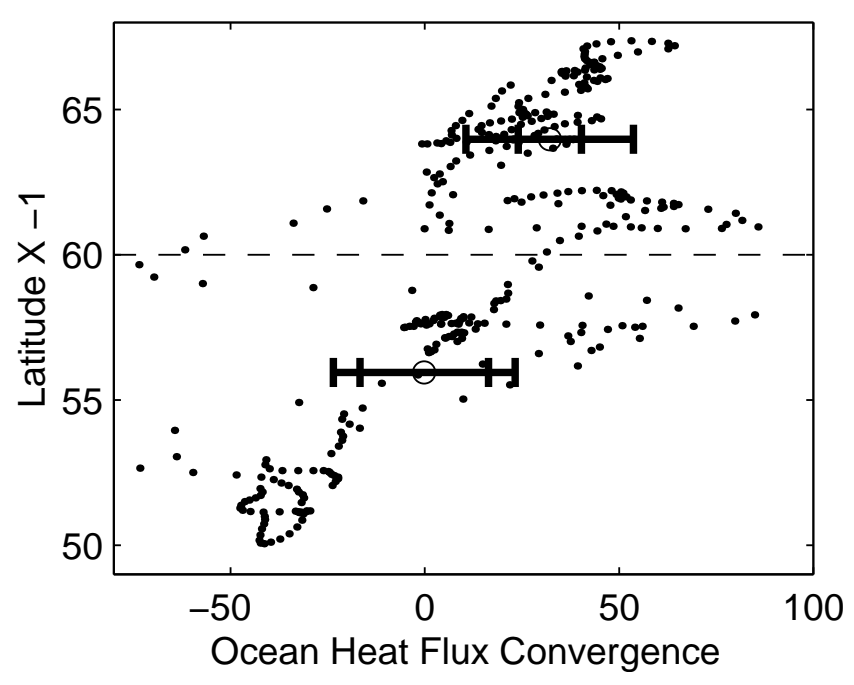

Figure 11. Scatter plot as in Fig. 7, but for the southern hemisphere and with error bars shown for groups of points above and below $60^{\circ} \mathrm{S}$.

defined in Fig. 6. There is a correspondence between the relative amount of heating by the ocean and the latitude of the region, as was noted for the northern hemisphere.

Fig. 11 shows a scatter plot of the latitude of the ice edge and the OHFC in the vicinity as was given for the northern hemisphere. The ice edge in the southern hemisphere spans a smaller interval of latitude than in the northern hemisphere, and there are no regions that experience drift speeds as large as in the East Greenland Current. As in the northern hemisphere, the points are correlated $\left(r^{2}=0.35\right)$, but again it is not clear how to asses the number of independent degrees of freedom in the data. We have broken the points in Fig. 11 into just two groups consisting of latitudes north and south of $60^{\circ} \mathrm{S}$, which generally also lie along eastern and western longitudes, respectively. With the latitudes separated in this way, the mean OHFC along the ice edge is significant different at the $95 \%$ confidence level along the ice edge for the two latitude groups.

As was mentioned at the start of section 4.2 , the southern hemisphere ice in CCSM2 is too extensive in winter in the Atlantic sector. Without observations for comparison, we can only speculate which terms are responsible for model biases. We have made a case for a relationship between OHFC and the latitude of the ice edge. Obviously, increasing the South Atlantic OHFC where the ice is too extensive would reduce the coverage, but so would increasing atmospheric heat convergence or decreasing the northward component of the wind stress. As all of these variables are mutually related, it is not possible to point to any one of them as the source of the bias. 
(a) Absorbed SW

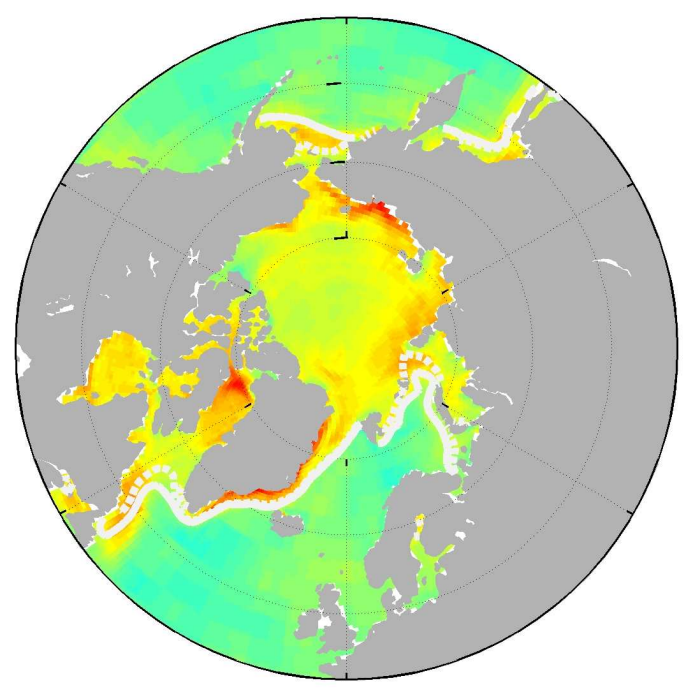

(b) Ocean Heat Flux Convergence
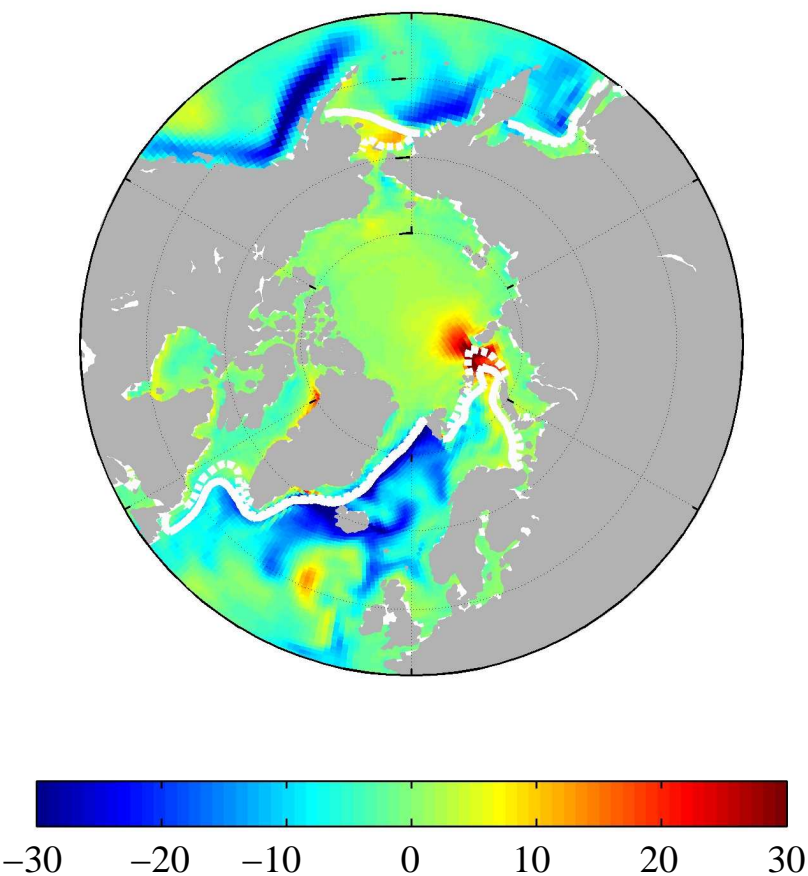

(c) Absorbed SW

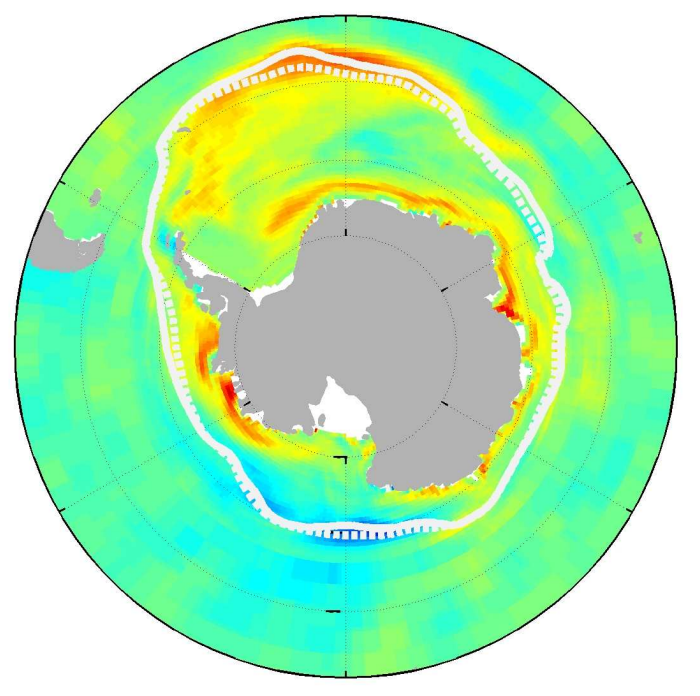

(d) Ocean Heat Flux Convergence
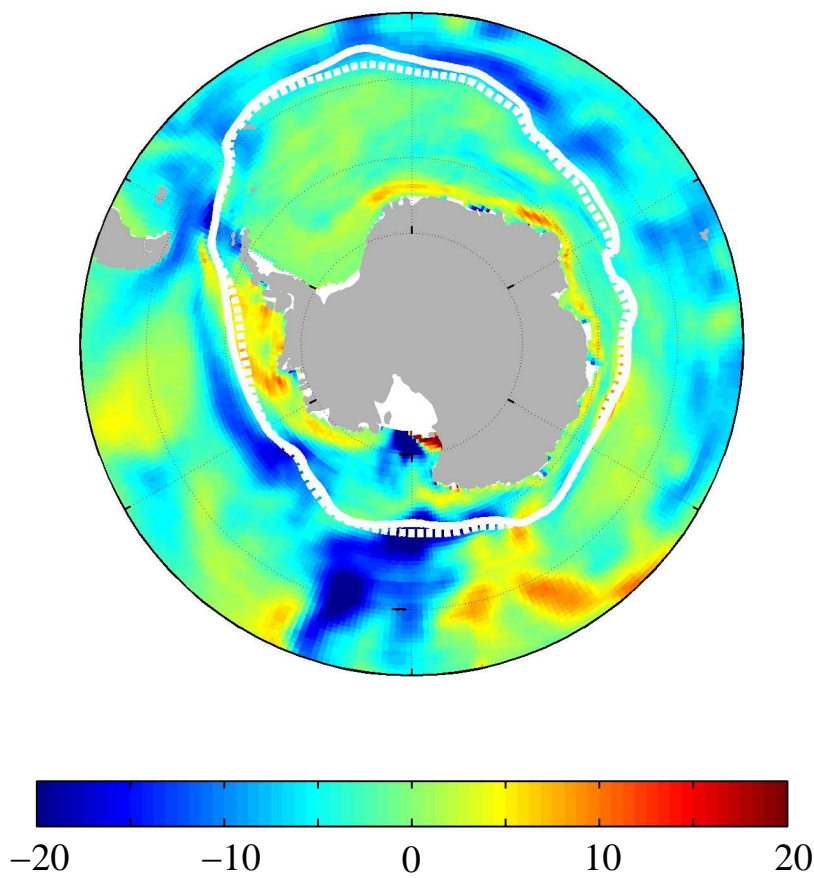

Figure 12. Difference between simulation with $2 \mathrm{XCO}_{2}$ and control in the sources of heating (in $\mathrm{W} \mathrm{m}^{-2}$ ) to the annual-mean ocean heat budget, as in Fig. 5. The wintertime (Jan.-Mar.) mean ice edge is shown for both simulations with $2 \mathrm{XCO}_{2}$ as dashed. 

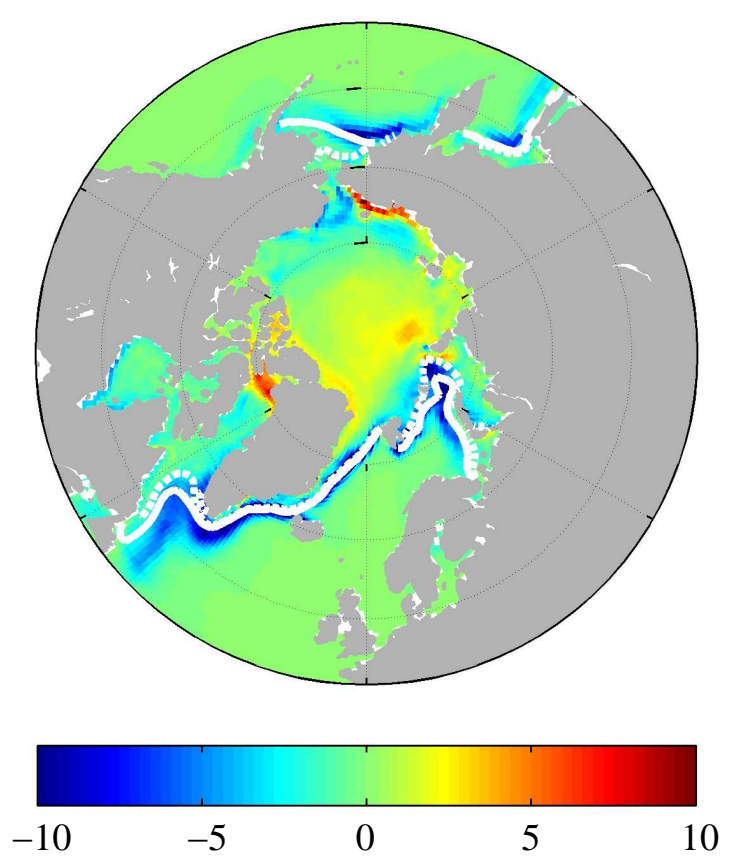
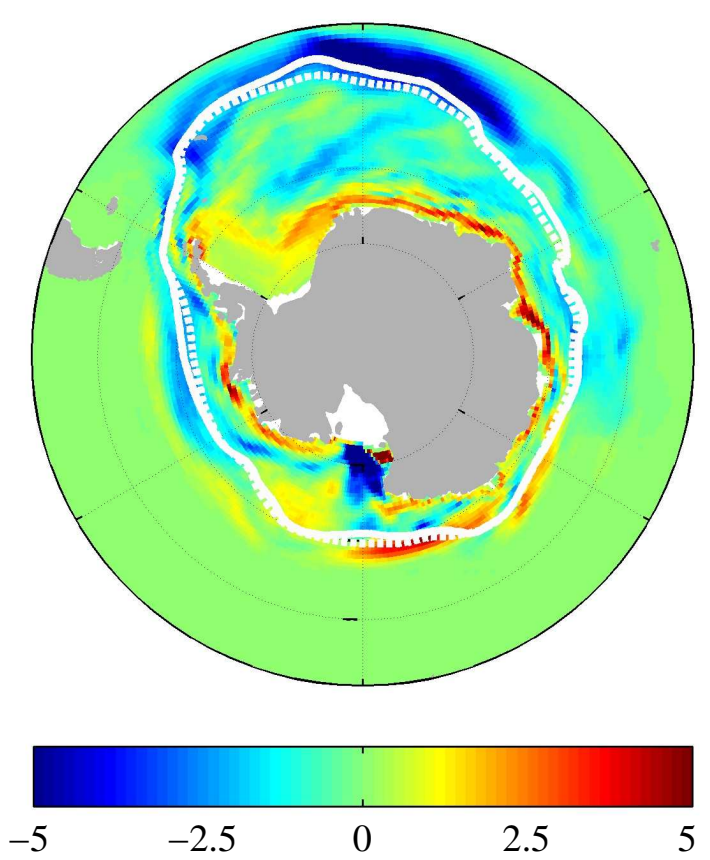

Figure 13. Difference between simulation with $2 \mathrm{XCO}_{2}$ and control in the ocean-ice heat flux. The wintertime mean ice edge is shown for both simulations with $2 \mathrm{XCO}_{2}$ as dashed.

\section{Changes under increased $\mathrm{CO}_{2}$}

One of our motivations for investigating processes that control the ice edge is to understand how the ice edge might change under increased radiative forcing. A reduction in ice cover is one of the changes predicted with increased greenhouse gases (GHG), but so too is a decrease in ocean heat transport in mid-latitudes in most models [Houghton et al., 2001]. Analysis of an integration forced with increasing GHG levels is an opportunity to further investigate what controls the mean position of the ice edge.

Here we examine the model response to increasing $\mathrm{CO}_{2}$ at the rate of $1 \%$ per year for 80 yrs by computing averages over the last 20 years (i.e., at the time of $\mathrm{CO}_{2}$ doubling). In section 2 , we described an error in the method used to increase $\mathrm{CO}_{2}$ in CCSM2 that results in an underestimate in the magnitude of the response to doubling $\mathrm{CO}_{2}$ of approximately $10 \%$.

Figure 12 shows the change in the wintertime seaice edge and the difference between the annual mean OHFC and solar absorption by the ocean between the simulation with $2 \mathrm{XCO}_{2}$ and the control in CCSM2. In most regions near the ice edge, the OHFC decreases more than the solar absorption increases. The changes in the ocean heat budget shown in Fig. 12 give rise to a reduction in the ocean-ice heat flux in most regions along the ice edge (see Fig. 13). This reduction indicates that changes to the OHFC outweigh the increased shortwave absorption.

The wintertime sea ice edge appears to change lit- tle from the control climate to the $2 \mathrm{XCO}_{2}$ climate in either hemisphere. This is due chiefly to two effects: (1) a negative feedback whereby sea ice renews itself quickly because the growth rate depends inversely on ice thickness [see Gordon and O'Farrell, 1997] and (2) the decrease in OHFC near the ice edge. The ice actually advances north of the Ross Sea, where the OHFC decreases more than any other place along the ice edge in the southern hemisphere. In contrast, the regions where the ice recedes the most (i.e., the eastern Bering Sea, the Labrador Sea, the Barents Sea, and the eastern side of Antarctica) are places where the OHFC decreases the least.

Figure 14 shows scatter plots of the change in the latitude of ice edge and the change in the OHFC in the vicinity of the ice edge. The correlation coefficient for the northern hemisphere is 0.72 and for the southern hemisphere it is 0.40 . It is difficult to know if these are significant, because as mentioned previously it is not clear how to estimate the number of independent degrees of freedom in the data. Nonetheless the figures suggest that reductions in the OHFC counteract some of the influence of the increased longwave forcing and icealbedo feedback associated with increased GHGs and supports the conclusions we have drawn from the control climate simulation - that is the position of the seaice edge is a strong function of the OHFC.

It is noteworthy that the OHFC increases in some regions poleward of the annual mean sea ice edge (see Figure 12). Because the ocean is not warming appreciably under the ice (not shown), the increase in OHFC 

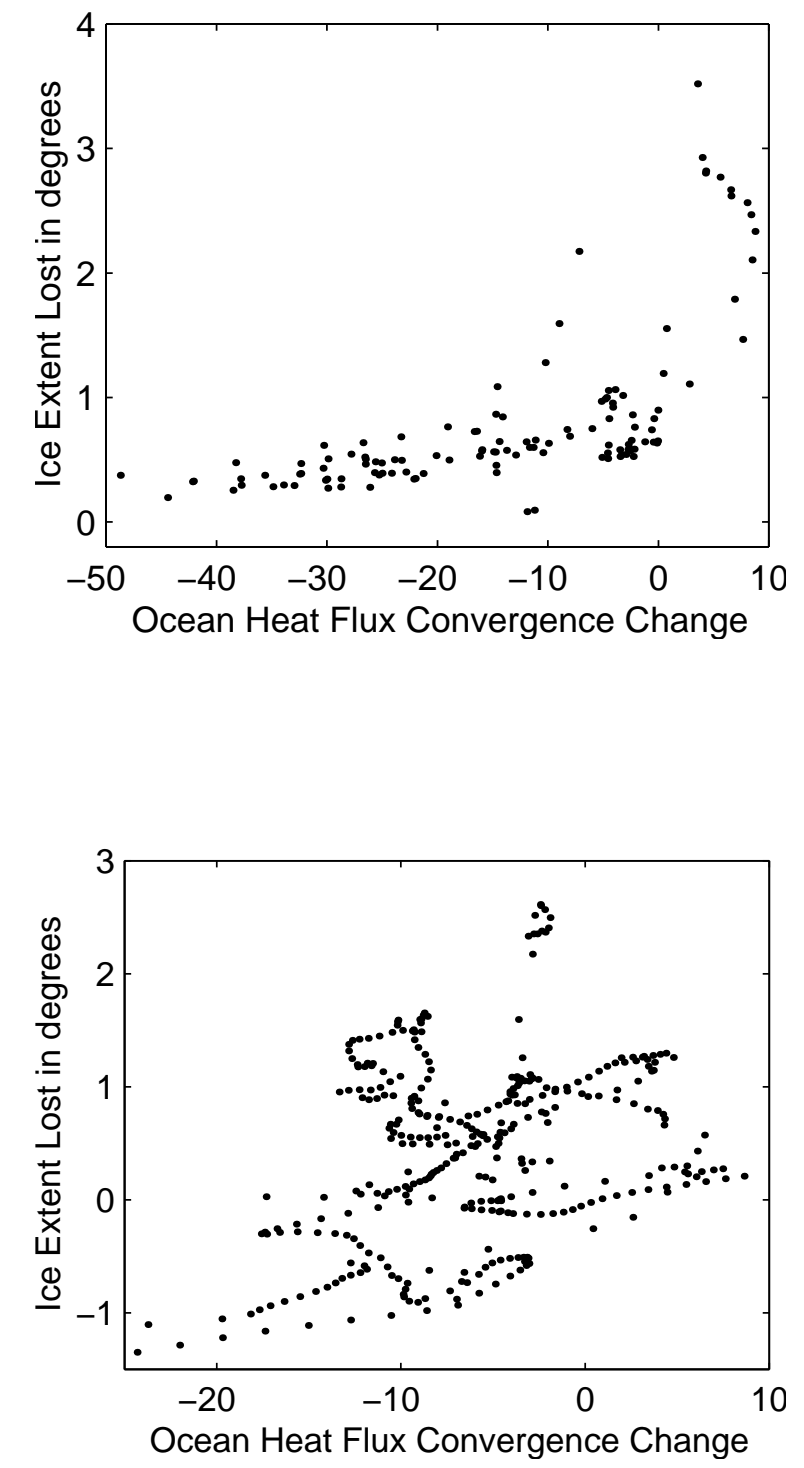

Figure 14. Scatter plot of the change in latitude of annual mean ice edge and change in the annual mean ocean heat flux convergence at the ice edge in response to doubling $\mathrm{CO}_{2}$ for the northern (a) and southern (b) hemispheres. The latitude of the ice edge is taken at $1^{\circ}$ intervals of longitude where unobstructed by coastlines. The OHFC is averaged over the same longitude and for latitudes that span the change in the position of the ice edge.

must be accompanied by a net increase in the surface heat loss from the ocean. In the warmer climate, the sea ice is generally thinner and there is more open water on the annual mean. These changes in the sea ice give rise to an increase in sensible heat loss through leads and conduction through the ice that is even greater than the the increase in net radiation into the surface in CCSM2.

\section{Conclusions}

One of the most striking similarities in the behavior of ice in the marginal ice zone in both hemispheres in CCSM2 is the year-round dominance of basal and lateral melt over top surface melt. Ice is often transported into regions where the ocean temperature is above the freezing temperature and/or heat is transported by the ocean under the ice, which causes year-round basal and lateral melt at the ice margin. Primarily two sources supply heat locally to the ocean vertical column: solar absorption and OHFC. Proportions of heating in the marginal ice zone by these two sources, shown in table 1 , indicate that the latitudinal position of the ice edge for each hemisphere taken individually depends roughly on the relative strength of the ocean heat flux covergence.

According to this simple picture, the sea ice edge in the Labrador ought to be even further south than in the Okhotsk Sea, which is not the case. Obviously other factors contribute to the latitudinal distribution such as the cold Siberian winds that cool the Okhotsk Sea compared to the marine air impinging on the southern margin of the Labrador Sea.

The strength of the OHFC is the most likely explanation for maintaining ice-free conditions in the Norwegian Sea and ice coverage in the Bering Sea, although these two regions share nearly the same latitude. The OHFC is approximately $200 \mathrm{~W} \mathrm{~m}^{-2}$ in the Norwegian Sea compared to approximately $40 \mathrm{~W} \mathrm{~m}^{-2}$ in the Bering Sea. By extension the Greenland Sea in CCSM2 ought to be ice-free altogether. However, southward ice advection into the Greenland Sea is much larger than elsewhere in the northern hemisphere and maintains the ice coverage there.

How can we be certain that the position of the ice edge itself isn't controlling the OHFC? In a few regions, we find that the ice edge is heavily influenced by cold air advection and ice motion. However, the model estimates of the volume budget do not generally support a consistently strong relationship between ice dynamics and the position of the ice edge.

Why do basal and lateral melt exceed top surface melt at the ice margin, even where the OHFC is small? The answer is simply that ice-free ocean absorbs about five to ten times more shortwave radiation than sea ice under typical melting conditions, so it is unsurprising that incoming shortwave radiation supplies more heat to the ocean (and hence basal and lateral melt) than to the ice upper surface (and hence top melt) in a region that is ice-free for at least some portion of the year.

It is often said that sea ice in the southern hemisphere melts primarily on the bottom [Gordon, 1981]. Our study shows that this is true in CCSM2 as well. 
Our analysis shows that shortwave absorption is proportionally a larger contribution than OHFC in the marginal ice zone in the Southern Ocean of CCSM2. However, the OHFC is on average about $12 \mathrm{~W} \mathrm{~m}^{-2}$ over portions of the Southern Ocean that are sea ice covered in winter. In contrast, the OHFC under ice in the Arctic Basin is approximately zero.

According to our analysis of CCSM2, the OHFC is a key player in controlling the position of the ice edge. Where the OHFC is large, the ice edge tends to be closest to the pole and the ice edge moves little over the seasonal cycle (i.e., the marginal ice zone is narrow). Where the OHFC is modest, but nonzero, the ice is mostly seasonal, extends to relatively low latitudes in winter, and retreats a long distance in summer. In the present day climate, thick perennial ice only exists where the OHFC is approximately zero.

This picture holds in a climate subject to increased $\mathrm{CO}_{2}$ forcing upto (at least) twice pre-industrial levels in CCSM2. The OHFC near the ice edge is generally weaker in the warmer climate, and its influence on the ice edge partially defeats the increase in surface radiative forcing. However under the perennial ice pack, in some areas within the marginal ice zone, the OHFC increases under increased $\mathrm{CO}_{2}$, which tends to create conditions more favorable for seasonal ice coverage throughout the polar oceans.

Acknowledgments. We thank Knut Aagaard, David Battisti, Norbert Untersteiner, and Rebecca Woodgate for helpful discussion. We thank Chris Bretherton for assistance with statistics. The authors gratefully acknowledge the support of the National Science Foundation through grants OPP0084287 (CMB and REM), ATM0304662 (CMB), and OPP0084273 (MMH). ECH was funded through the Climate Change Prediction Program of the Department of Energy's Office of Biological and Environmental Research.

\section{References}

Bitz, C. M., M. M. Holland, A. J. Weaver and M. Eby, 2001: Simulating the ice-thickness distribution in a coupled climate model. J. Geophys. Res., 106, 2441-2464.

Bitz, C. M. and W. H. Lipscomb, 1999: An energyconserving thermodynamic model of sea ice. J. Geophys. Res., 104, 15,669-15,677.

Bonan, G. B., K. Oleson, M. Vertenstein, S. Levis, X. Zeng, Y. Dai, R. Dickinson and Z.-L.Yang, 2002: Community land model coupled to the ncar community climate model. J. Climate, submitted.

Briegleb, B. P., C. M. Bitz, E. C. Hunke, W. H. Lipscomb and J. L. Schramm, 2002: Description of the Community Climate System Model Version 2 Sea Ice Model. http://www.ccsm.ucar.edu/models/ccsm2.0/csim/, pp. 60.

Chiang, J. C. H., M. Biasutti and D. S. Battisti, 2003: Sensitivity of the Atlantic ITCZ to conditions during the Last Glacial Maximum. Paleoceanography, 18, 10.1029/2003PA000916.
Collins, W. D., C. M. Bitz, M. Blackmon, G. B. . Bonan, C. S. Bretherton, J. A. Carton, P. Chang, S. Doney, J. J. Hack, T. Henderson, J. T. Kiehl, W. G. Large, D. McKenna, B. D. Santer, and R. Smith, 2005: The Community Climate System Model, CCSM3. J. Climate, $18, \mathrm{X}$.

Collins, W. D., J. J. Hack, B. A. Boville, P. J. Rasch, D. L. Williamson, J. T. Kiehl, B. P. Briegleb, C. M. Bitz, S. Lin and R. B. Rood, 2002: Description of the NCAR Community Atmosphere Model (CAM2). http://www.ccsm.ucar.edu/models/atmcam/docs/cam2.0/ pp. 189.

Comiso, J. C., 1995: SSM/I concentrations using the Bootstrap Algorithm. Tech. Rep. RP 1380, 40pp, NASA, Technical Report.

da Silva, A. M., C. C. Young and S. Levitus, 1994: Atlas of surface marine data 1994. Volume 1. Algorithms and Procedures. Tech. Rep. NOAA NESDIS 6, National Oceanographic and Atmospheric Administration, United States Department of Commerce, 83pp.

Danabasoglu, G., 1998: On the wind driven circulation of the uncoupled and coupled NCAR Climate System Model ocean model. J. Climate, 11, 1442-1454.

Fang, Z. and J. M. Wallace, 1994: Arctic sea ice variability on a timescale of weeks and its relation to atmospheric forcing. J. Climate, 7, 1897-1913.

Gent, P. R., A. P. Craig, C. M. Bitz and J. W. Weatherly, 2002: Parameterization improvements in an eddypermitting ocean model. J. Climate, 13, 1447-1459.

Gent, P. R. and G. Danabasoglu, 2004: Heat uptake and the thermohaline circulation in the Community Climate System Model, Version 2. J. Climate, 17, 4058-4069.

Gent, P. R. and J. C. McWilliams, 1990: Isopycnal mixing in ocean circulation models. J. Phys. Oceanogr., 20, 150155.

Gordon, A. L., 1981: Seasonality of Southern Ocean sea ice. J. Geophys. Res., 86, 4193-4197.

Gordon, A. L. and B. A. Huber, 1984: Thermohaline stratification below the Southern Ocean sea ice. J. Geophys. Res., 89, 641-648.

Gordon, A. L. and B. A. Huber, 1990: Southern Ocean winter mixed layer. J. Geophys. Res., 95, 11,655-11,672.

Gordon, H. B. and S. P. O'Farrell, 1997: Transient climate change in the CSIRO coupled model with dynamics sea ice. Mon. Wea. Rev., 125, 875-907.

Hibler, W. D. I. and S. F. Ackley, 1983: Numerical simulations of the Weddell Sea pack ice. J. Geophys. Res., 88, 2873-2887.

Hibler III, W. D., 1986: Ice dynamics. in N. Untersteiner, editor, The Geophysics of Sea Ice, Vol. 146, pp. 577-640. NATO ASI Series B, Physics, Plenum, New York, London.

Hibler III, W. D. and K. Bryan, 1987: A diagnostic iceocean model. J. Phys. Oceanogr., 17, 987-1015.

Holland, M. M., C. Bitz, M. Eby and A. Weaver, 2001a: Low frequency variability of the North Atlantic/Arctic climate system in a coupled ocean-sea ice-atmosphere model. $J$. Climate, 14, 656-675.

Holland, M. M., C. Bitz and A. Weaver, 2001b: The influence of sea ice physics on simulations of climate change. J. Geophys. Res., 106, 2441-2464.

Houghton et al., 2001: IPCC third assessment report: Climate change 2001: The scientific basis. Cambridge University Press, Cambridge, UK, 944pp. 
Hunke, E. C. and J. K. Dukowicz, 2002: The elastic-viscousplastic sea ice dynamics model in general orthogonal curvilinear coordinates on a sphere - incorporation of metric terms. Mon. Wea. Rev., 130, 1848-1865.

Ingram, W. J., C. A. Wilson and J. Mitchell, 1989: Modeling climate change: An assessment of sea ice and surface albedo feedbacks. J. Geophys. Res., 94, 8609-22.

Kiehl, J. and P. Gent, 2004: The Community Climate System Model, version two. J. Climate, 17, 3666-3682.

Large, W. G., J. McWilliams and S. Doney, 1994: Oceanic vertical mixing: A review and a model with a nonlocal boundary layer parameterization. Rev. Geophys., 32, 363-403.

Lewis, J. P., A. J. Weaver, S. T. Johnson and M. Eby, 2003: The Neoproterozoic "snowball Earth"": Dynamic sea ice cover over a quiescent ocean. Paleoceanogr., 18, doi:10.1029/2002PA00078.

Lipscomb, W. H., 2001: Remapping the thickness distribution in sea ice models. J. Geophys. Res., 106, 13,98914,000 .

Liu, J., D. Martinson, X. Yuan and D. Rind, 2002: Evaluating Antarctic sea ice variability and its teleconnections in global climate models. Inter. Jour. Clim., 22, 885-900.

Lytle, V. I. and S. F. Ackley, 1996: Heat flux through sea ice in the western Weddell Sea: Convective and conductive transfer processes. J. Geophys. Res., 101, 8853-8868.

Magnusdotter, G., C. Deser and R. Saravanan, 2004: The effects of North Atlantic SST and sea ice anomlies on the winter circulation in CCM3. Part I: Main features and storm track characteristics of the response. J. Climate, 17, 857-876.

Manabe, S. and R. J. Stouffer, 1980: Sensitivity of a global climate model to an increase of $\mathrm{CO}_{2}$ concentration in the atmosphere. J. Geophys. Res., 85, 5529-5554.

Martinson, D., 1990: Evolution of the Southern-Ocean winter mixed layer and sea ice - open ocean deep-water formation and ventilation. J. Geophys. Res., 95, 1164111654.

Maykut, G. A. and M. G. McPhee, 1995: Solar heating of the Arctic mixed layer. J. Geophys. Res., 100, 24,69124,703 .

McPhee, M. G., C. Kottmeier and J. Morison, 1999: Ocean heat flux in the central weddell sea during winter. J. Phys. Oceanogr., 29, 1166-1179.

Parkinson, C. L., D. J. Cavalieri, P. Gloersen, H. J. Zwally and J. C. Comiso, 1999: Variability of the arctic sea ice cover 1978-1996. J. Geophys. Res., 104, 20,837-20,856.

Parkinson, C. L. and W. M. Washington, 1979: A largescale numerical model of sea ice. J. Geophys. Res., 84, 311-337.

Perovich, D. K. and Coauthers, 1999: Year on ice give climate insights. EOS, Trans., Amer. Geophys. Union, 80, 481,485-486.

Poulsen, C., R. T. Pierrehumbert and R. L. Jacobs, 2001: Impact of ocean dynamics on the simulation of the Neoproterozoic"snowball Earth". Geophys. Res. Lett., 28, 1575-1578.

Rasch, P. J. and J. E. Kristjánsson, 1998: A comparison of the CCM3 model climate using diagnosed and predicted condensate parameterizations. J. Climate, 11, 1587-1614.

Rudels, B., 1989: Haline convection in the Greenland Sea. Deep Sea Res., Part A, 37, 1491-1511.
Seager, R., D. S. Battisti, M. Gordon, N. Naik, A. C. Clement and M. A. Cane, 2002: Is the gulf stream responsible for europe's mild winters? Q. J. R. Meteorol. Soc., 128, 2563-86.

Semtner, A. J., 1987: A numerical study of sea ice and ocean circulation in the Arctic. J. Geophys. Oceanogr., 17, 1077-1099.

Smith, L. M., G. H. Miller, B. Otto-Bliesner and S.-I. Shin, 2003: Sensitivity of the Northern Hemisphere climate system to extreme changes in Holocene Arctic sea ice. Quat. Sci. Rev., 22, 645-658.

Smith, R. D., J. K. Dukowicz and R. C. Malone, 1992: Parallel ocean circulation modeling. Physica D., 60, 38-61.

Steele, M. and G. M. Flato, 1999: Sea ice growth, melt, and modeling: A survey. in E. Lewis, editor, The Arctic Ocean Freshwater Budget, pp. 549-589. NATO ARW Volume, Netherlands.

Steele, M., R. Morley and W. Ermold, 2001: PHC: A global ocean hydrography with a high quality arctic ocean. $J$. Climate, 14, 2079-2087.

Untersteiner, N., 1961: On the mass and heat budget of arctic sea ice. Arch. Meteorol. Geophys. Bioklimatol., A, 12, 151-182.

Untersteiner, N., 1975: Sea ice and ice sheets and their role in climatic variations. in The Physical basis of climate and climatic modelling, pp. 206-224. Global Atmospheric Research Project (GARP). Publication series no. 16, World Meteorological Organization / International Council of Scientific Unions.

Untersteiner, N., 1988: On the ice and heat balance in fram strait. J. Geophys. Res., 93, 527-31.

Visbeck, M., J. Fischer and F. Schott, 1995: Preconditioning the Greenland Sea for deep convection: Ice formation and ice drift. J. Geophys. Res., 100, 18,489-18,502.

Visbeck, M., J. Marshall, T. Haine and M. Spall, 1997: Specification of eddy transfer coefficients in coarse-resolution ocean circulation models. J. Phys. Oceanogr., 27, 381402.

Wadhams, P., 1981: The ice cover in the Greenland and Norwegian Seas. Rev. Geophys., 19, 345-393.

Walsh, J. E., W. D. Hibler III and B. Ross, 1985: Numerical simultion of northern hemisphere sea ice variability 19511980. J. Geophys. Res., 90, 4847-4865.

Walsh, J. E. and C. M. Johnson, 1979: An analysis of Arctic sea ice fluctuations. J. Phys. Oceanogr., 9, 580-591.

Winton, M., 2003: On the climatic impact of ocean circulation. J. Climate, p. in press.

Cecilia M. Bitz and Richard E. Moritz, Polar Science Center, University of Washington, 1013 NE 40th St., Seattle, WA, 98105

Marika M. Holland, National Center for Atmospheric Research, P.O. Box 5000, Boulder, CO 8XXXX

Elizabeth C. Hunke, Los Alamos National Labs, Los Alamos, NM

This preprint was prepared with AGU's LATEX macros v5.01, with the extension package ' $\mathrm{AGU}^{++}$' by $\mathrm{P}$. W. Daly, version $1.6 \mathrm{~b}$ from 1999/08/19. 